

\title{
SHALLOW-WATER PERFORMANCE OF A PLANING BOAT
}

\author{
by \\ Andras Istvan Toro \\ Student Member of SNAME \\ Student at The University of Michigan
}

For Presentation at the Annual Meeting of Southeast Section of SNAME

April 25, 1969 


\section{ABSTRACT}

The results of a planing-boat model resistance test program conducted at four different water depths, including deep water, and three locations of LCG are presented. The sensitivity of the resistance of a planing boat to shallow water through the critical speed range $\left(\mathrm{F}_{\mathrm{nh}}=0.5-3.5\right)$ is analyzed and compared with the deep-water results. Near the critical speed (subplaning), horsepower increases dramatically due to shallowness, but at planing speeds the power is reduced. The paper also gives extrapolated results for a boat of 100,000 lb gross weight. Model and full-scale results are presented in convenient graphical and tabular form for further use. 


\section{INTRODUCTION}

At the present time, very limited test results which enable a planing-boat designer to approximate resistance in shallow water are available. Several systematic series and the planing-prism data give powering estimates only for deep-water application. Shallow-water data is available only for displacement hulls. However, the resistance of a planing hull in shallow water can be significantly different than in deep water. The greatest effect of shallowness on trim, CG rise, and resistance is at relatively low $F_{\nabla}$ or speeds somewhat less than hump speeds, which is the general operating condition where trim, CG rise, and resistance are the most sensitive to speed changes. This is important even for a boat designed to normally operate at relatively high $F_{\nabla}$ and in deep water, since the low speeds such a boat would experience would be in channels, rivers, and harbors where the water is shallow.

The need for shallow-water data and the opportunity to investigate an interesting phenomenon led to tests of a Series 62 hull form in four different water depths and at three different LCG locations. The tests were performed at The University of Michigan Ship Hydrodynamics Laboratory in Ann Arbor, Michigan. 


\section{NOMENCLATURE*}

\begin{tabular}{|c|c|c|}
\hline$A_{p}$ & $=$ & $\begin{array}{l}\text { Projected planing-bottom area, excluding } \\
\text { area of external spray strip, sq ft }\end{array}$ \\
\hline${ }^{B} \mathrm{p}$ & $=$ & $\begin{array}{l}\text { Beam or breadth over chines, exluding ex- } \\
\text { ternal spray strip, ft }\end{array}$ \\
\hline${ }^{B}$ PA & $=$ & Mean Breadth over chines: $A_{P} / L_{P}$, ft \\
\hline $\mathrm{B}_{\mathrm{PT}}$ & $=$ & $\begin{array}{l}\text { Breadth over chines at transom, excluding } \\
\text { external spray strip, ft }\end{array}$ \\
\hline${ }^{B} \mathrm{PX}$ & $=$ & $\begin{array}{l}\text { Maximum breadth over chines, exluding ex- } \\
\text { ternal spray strip, ft }\end{array}$ \\
\hline BL & $=$ & Base line \\
\hline$b$ & $=$ & $\begin{array}{l}\text { Breadth over spray strips at longitudinal } \\
\text { location of center of gravity, ft }\end{array}$ \\
\hline CL & $=$ & Centerline \\
\hline CG & $=$ & Center of gravity \\
\hline $\mathrm{C}_{\mathrm{T}}$ & $=$ & Total resistance coefficient \\
\hline $\mathrm{C}_{\mathrm{R}}$ & $=$ & Residual resistance coefficient \\
\hline $\mathrm{h}$ & $=$ & Finite depth of water, ft \\
\hline $\mathrm{F}_{\mathrm{n}}$ & $=$ & Froude number based on length \\
\hline
\end{tabular}

* Nomenclature used is ITTC standard Symbols and that recommended in SNAME $T \& R$ Bulletin $1-23$. 


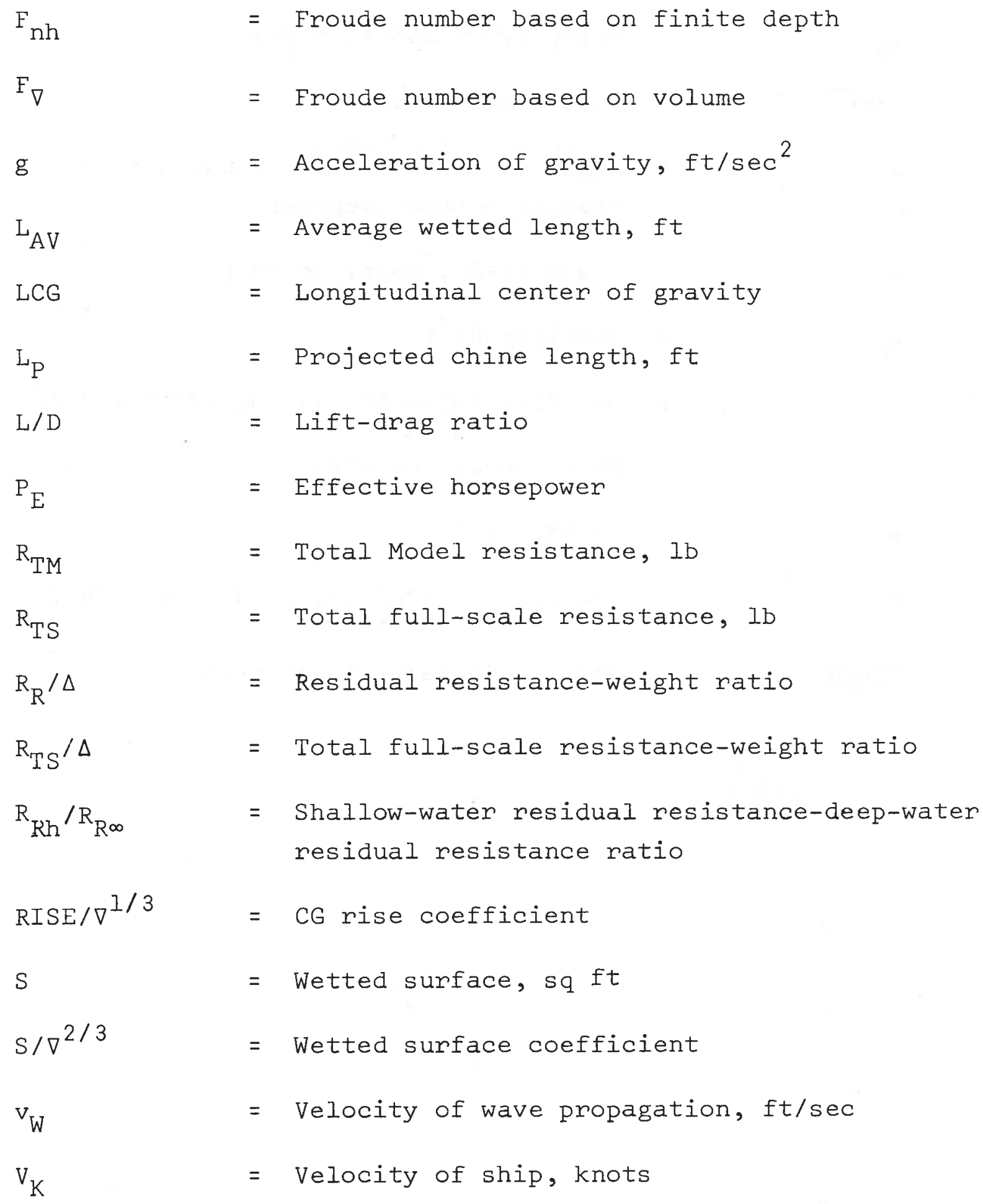




\begin{tabular}{|c|c|c|}
\hline$v_{M}$ & $=$ & Velocity of model, ft/sec \\
\hline $\mathrm{V} / \sqrt{\mathrm{L}}$ & $=$ & Speed-length ratio \\
\hline$\alpha$ & $=$ & $\begin{array}{l}\text { Angle of attack at after portion of } \\
\text { planing bottom, degrees }\end{array}$ \\
\hline$\lambda$ & $=$ & scale ratio, model to ship \\
\hline$\lambda_{\mathrm{W}}$ & $=$ & Wavelength, ft \\
\hline$\beta$ & $=$ & Deadrise angle of planing bottom, degrees \\
\hline$\rho$ & $=$ & Mass density of water \\
\hline$v$ & $=$ & Kinematic viscocity \\
\hline$\nabla$ & $=$ & Volumetric displacement at rest, cu ft \\
\hline$\nabla / A_{\mathrm{P}} \mathrm{h}$ & $=$ & Mean draft-water depth ratio \\
\hline
\end{tabular}




\title{
DESCRIPTION AND SCOPE OF THE TESTS
}

\author{
As mentioned previously, a Series 62 hull form \\ $\left(L_{\mathrm{P}} / \mathrm{B}_{\mathrm{PX}}=3.06\right)$ was selected (see Figure 1 ), as a repre- \\ sentative planing hull form.
}

Particulars of the Model No. 1174

$\begin{array}{llll}\mathrm{A}_{\mathrm{P}}, \text { ft } & =3.322 & \mathrm{~B}_{\mathrm{PX}} / \mathrm{B}_{\mathrm{P}} & =1.21 \\ \mathrm{~L}_{\mathrm{P}}, \mathrm{ft} & =3.50 & \mathrm{~B}_{\mathrm{PT}} / \mathrm{B}_{\mathrm{PX}} & =0.71 \\ \mathrm{~B}_{\mathrm{PA}}, \mathrm{ft} & & \text { Centroid of } \mathrm{A}_{\mathrm{P}}, \% \\ { }_{\mathrm{PX}}, \text { ft } & =1.144 & \mathrm{~L}_{\mathrm{P}} \text { Forward of Transom }=48.2 \\ { }_{\mathrm{BT}}, \mathrm{ft} & =0.810 & \\ \mathrm{~L}_{\mathrm{P}} / \mathrm{B}_{\mathrm{PA}} & =3.69 & \\ \mathrm{~L}_{\mathrm{P}} / \mathrm{B}_{\mathrm{PX}} & =3.06 & \end{array}$

The model was made of wood (sugar pine) and plastic spray strips were fitted on the hull as described in Reference [1], for details see Figure 1. The surface of the model was varnished, and for stimulating turbulent flow, a trip wire 0.035 inches in diameter was fitted on each side of the stem as described in Reference [1], also see Figure 1 for details. On the outside surface of the model, every station and half-station were marked for reading the solid-water wetted length and for obtaining wetted surface. 


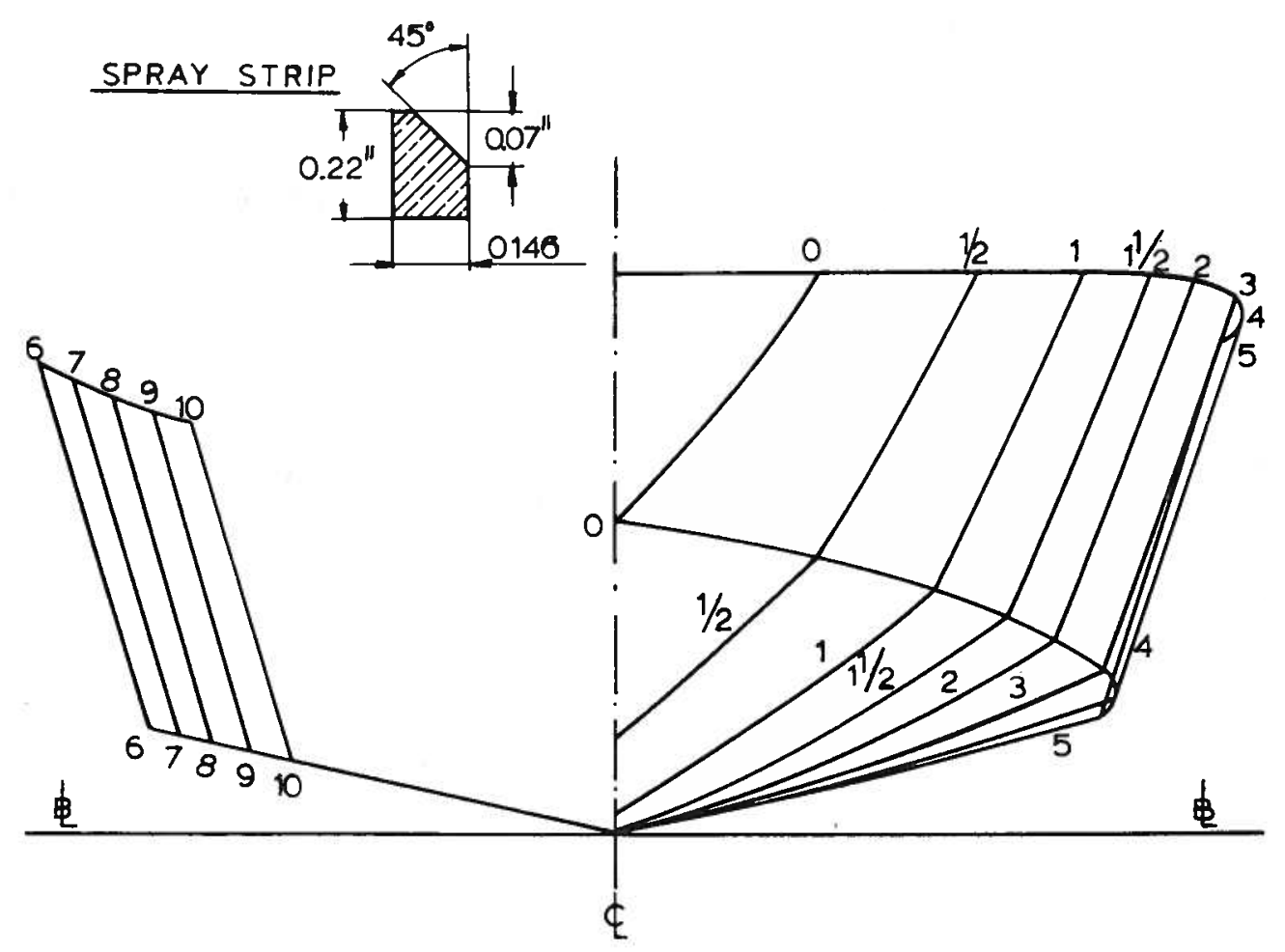

MODEL № 1174

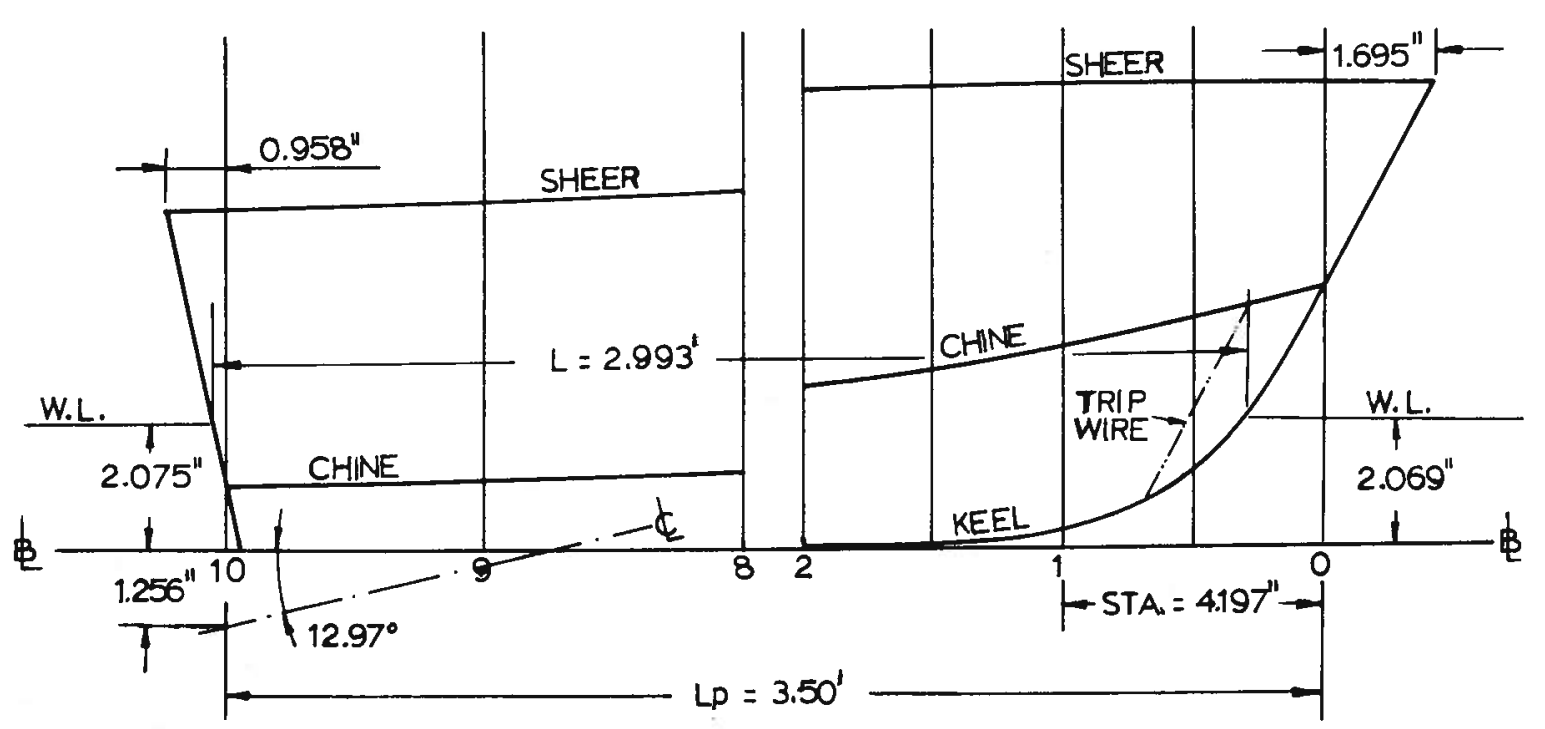

FIGURE 1 
A new multilever testing apparatus (Figure 2) was used to measure the towing force on the propeller shaft centerline. The apparatus automatically adjusted by a servo-system to coincide with the shaft line during each run. A switch was attached in the bottom of the model and set for the correct shaft inclination in the static condition. This was the neutral position of the switch, at which time no current was flowing. The tow rod acted as the sliding part of the switch. Whenever the hull trimmed up or down to a new running position, the switch moved out of its neutral position, thereby completing the servo-motor curcuit. The purpose of the motor was to drive the pivoting upper frame to the correct shaft position, at which time the servo-switch became neutral again.

Sinkage and trim were recorded from the same apparatus. For determining wetted surface and wetted length, photographs were taken (see Appendix).

The location of the longitudinal CG is defined as the distance of the LCG from the centroid of the area $A_{P}$, expressed as a percentage of the length $L_{P}$. For the tests, $2 \%, 6 \%$, and $10 \%$ were used.

The shallow-water depths were chosen to be $7.5,12.0$, and 20.0 inches model scale. In order to relate the shallow-water depth $(h)$ to the boat geometry, a new nondimensional 


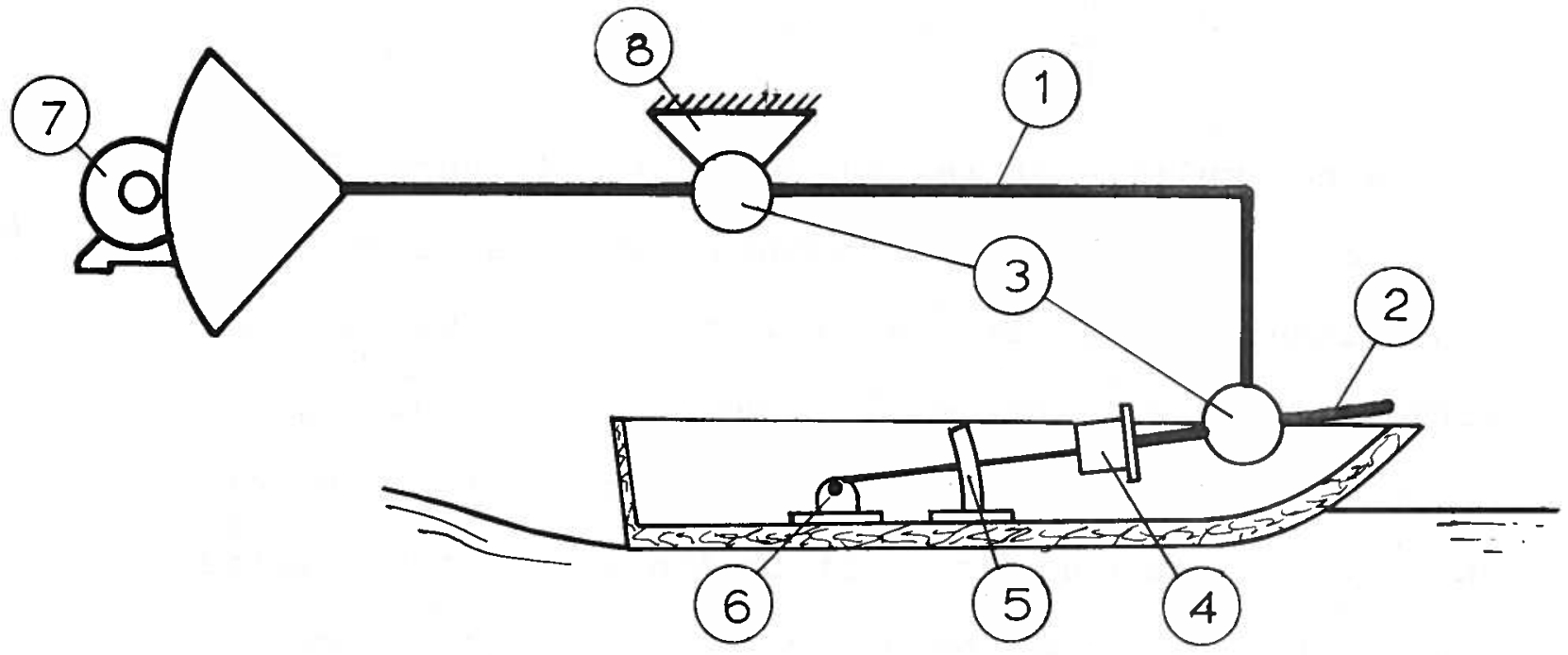

MULTI-LEVER TESTING APPARATUS

1. Pivoting upper frame.

2. Rotating lower frame.

3. Angle measuring pots.

4. Force measuring device.

5. Servo-switch.

6. Tow point.

7. Servo-motor.

8. Fix attachment to carriage.

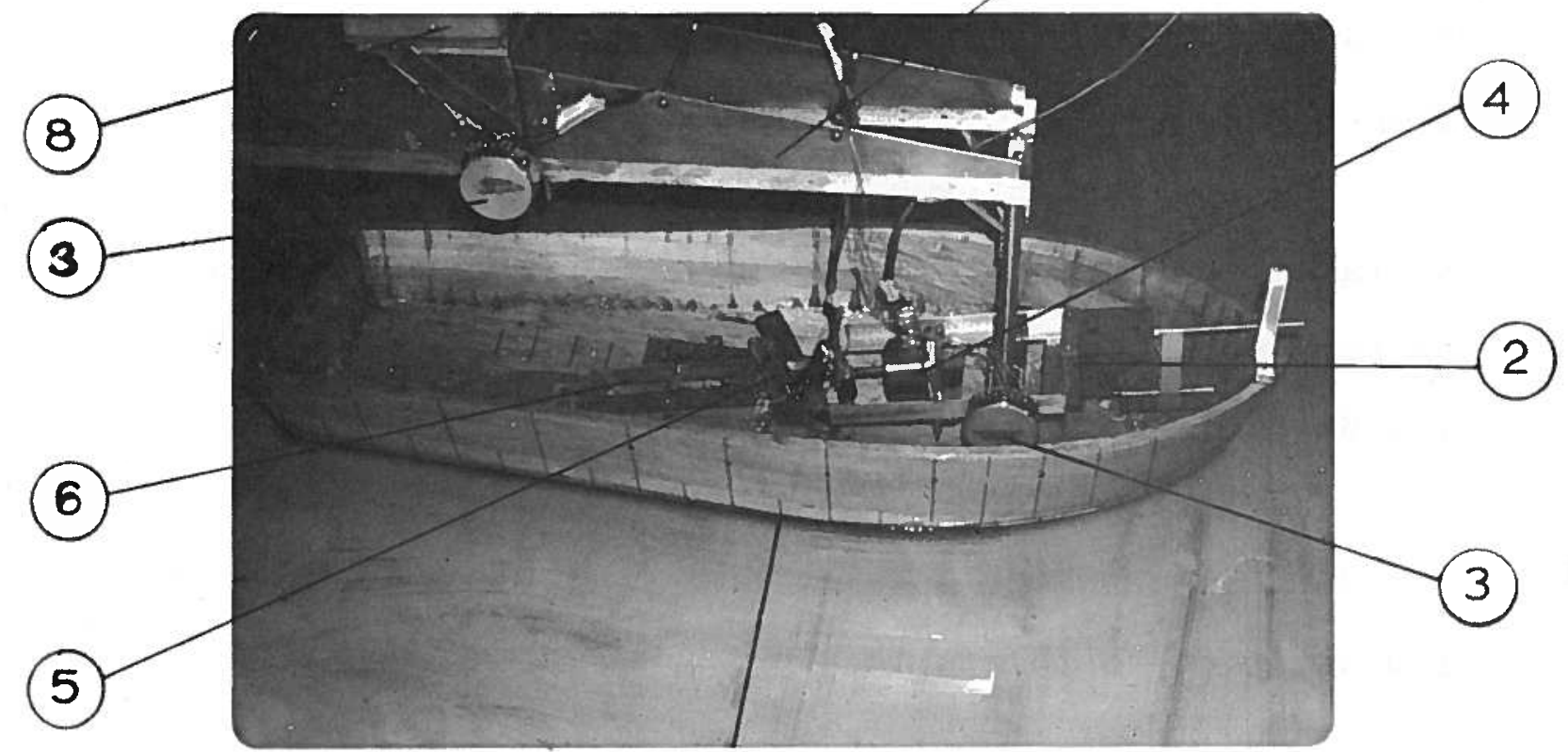


parameter is used, $\nabla / A_{P} h$. The mean draft-water depth parameter is independent of LCG position. The values of $\nabla / A_{P} h$ were $0.157,0.098$, and 0.059 , respectively, for decreasing water depth.

The length of the adjustable shallow-water bottom in the model basin is 90 feet. Variation of the bottom was $\pm 1 / 8$ inch. There was considered to be no leakage since the bottom was newly installed and made of rigid fiberglass panels.

\section{TEST RESULTS}

Tabulated model results for all the tests are given in the Appendix. The resistance data for all conditions have been expanded to a boat gross weight of 100,000 lb. This weight represents a somewhat large-sized motor yacht with a length of approximately 60 feet. The ATTC friction coefficients were used with zero correlation allowance.

Figures 3, 4, and 5 compare model values of resistance, trim, and CG rise at four water depths with each at the same LCG location. The effect of shallowness is evident by simple observation. 
Considering the shallow-water phenomenon in more detail for a boat moving in water of restricted depth but unrestricted width at $\mathrm{F}_{\mathrm{nh}} \simeq 1.0$, the water passing under the hull must speed up more than in deep water, which causes reduction in the pressure gradient and an increase in resistance with greater sinkage and trim. The shallower the water depth, the more pronouned is the effect.

The case with the least clearance under the transom was at the 10\% LCG location and in 7.5 inches of water. At the critical speed (near $F_{n h}=1.0$ ) the clearance was approximately 4.0 inches under the transom. In these conditions the water will not flow underneath the hull as easily as in deep water. The flow goes around the hull and sets up a different wave pattern, which is the other important shallow-water phenomenon. As explained in Reference [2], on page 320 , the wave pattern follows the law of dispersion of gravity waves.

The velocity of surface waves is given by

$$
\mathrm{v}_{W}^{2}=\left(\frac{g \lambda W}{2 \pi}\right) \tanh \frac{2 \pi h}{\lambda_{W}} .
$$

For shallow water (h small),

$$
\tanh \frac{2 \pi h}{\lambda_{W}}=\frac{2 \pi h}{\lambda_{W}}
$$




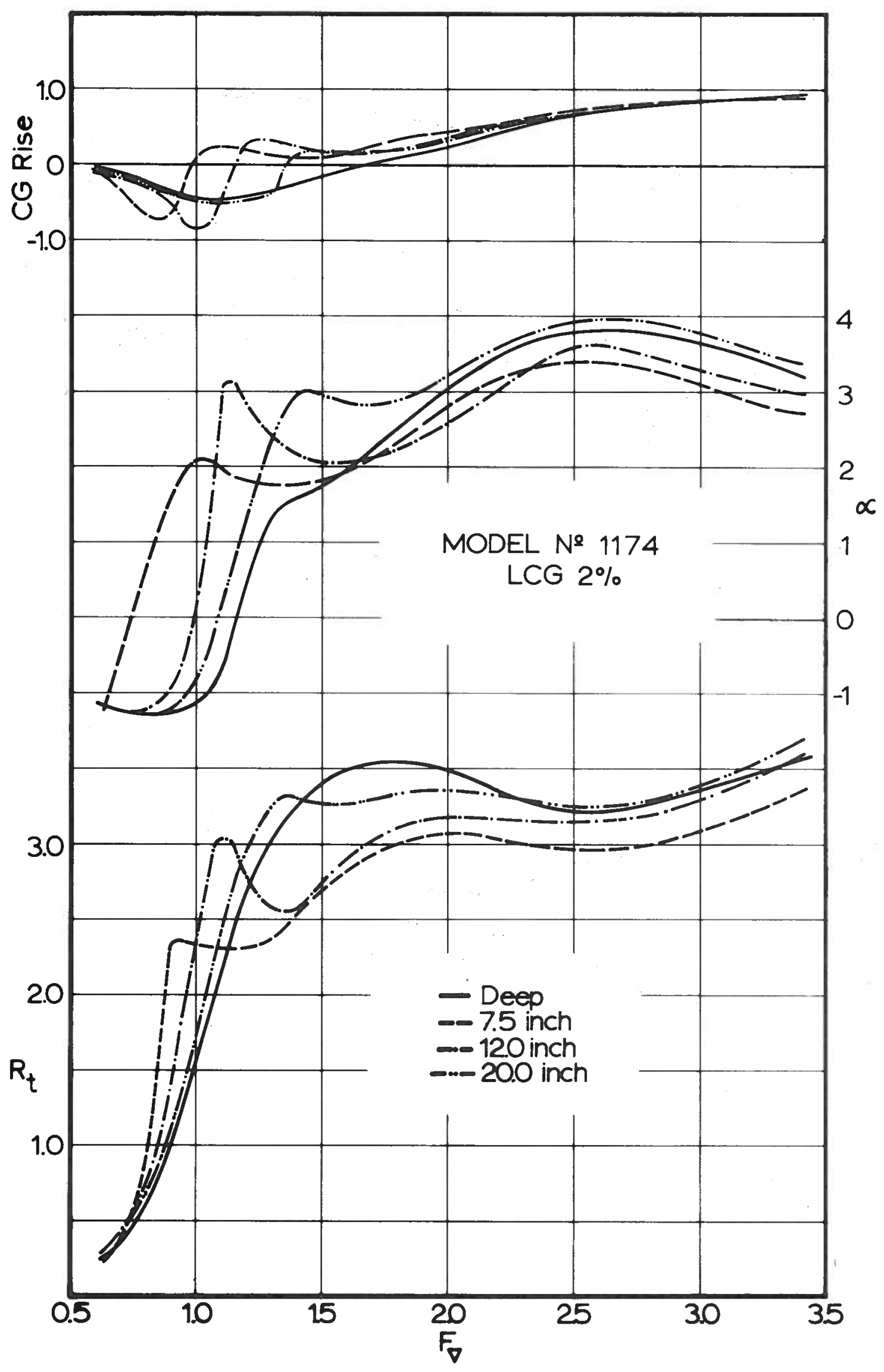

Figure 3 


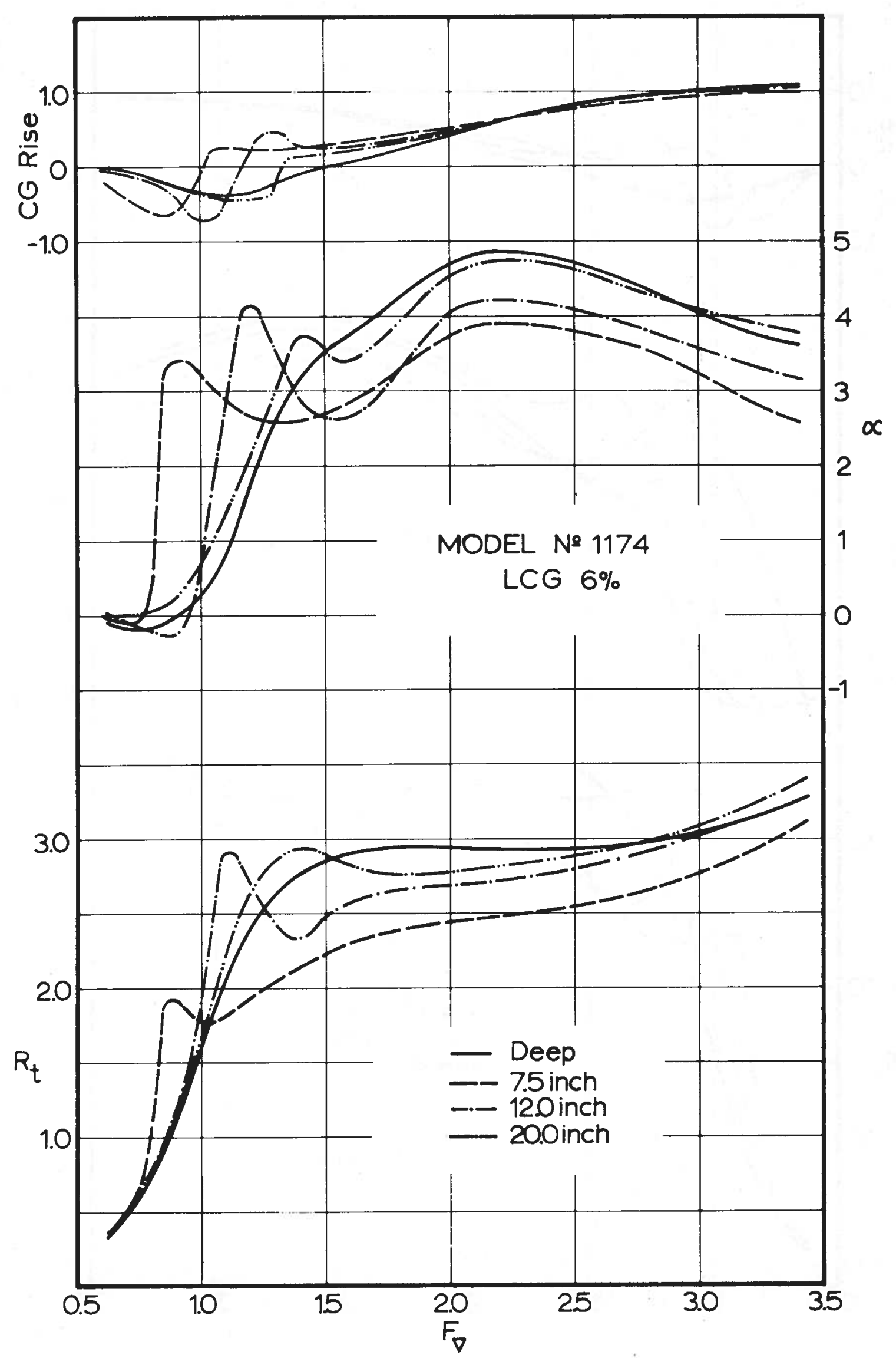

Figure 4 


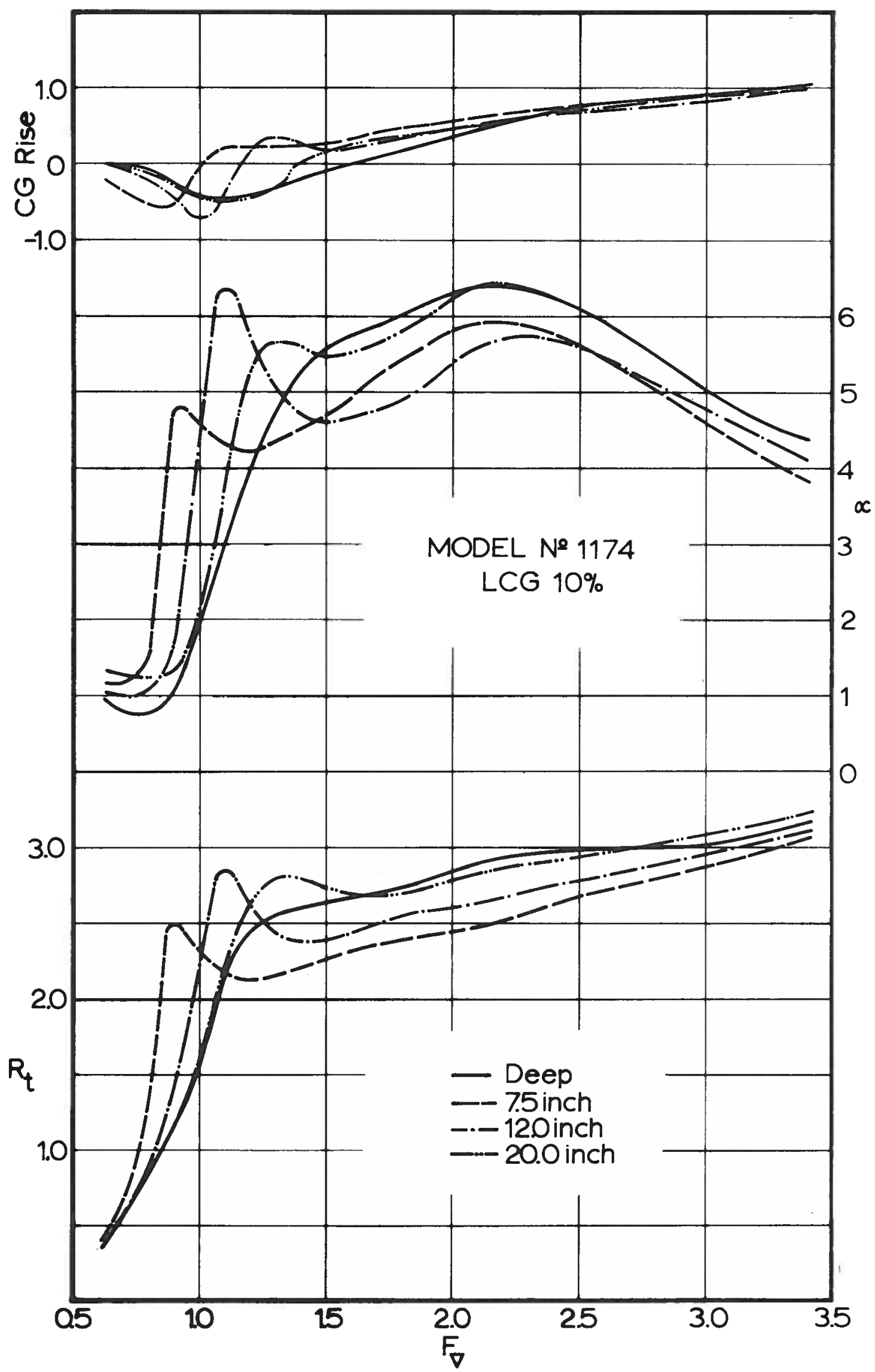

Figure 5 
and

$$
v_{W}=\sqrt{g h}
$$

or

$$
F_{\text {nh }}=1.0 .
$$

This means that for $\mathrm{F}_{\mathrm{nh}} \simeq 1.0$ the free waves generated by the boat travel with it and appear to form abreast of the boat. That is, the usual Kelvin angle is nearly $19^{\circ}$. At lower speeds (subcritical) the waves are oriented in the usual manner with an angle of $90^{\circ} 28^{\prime}$. At higher speeds (supercritical) the waves tend to reorient themselves to angles less than $90^{\circ}$, depending on speed. These different wave formations may be expected to represent wave energy losses different than in shallow water, hence alterations in wave resistance. The critical speed is when the residual resistance is greatest (Figure 6). Because of the trim-sensitive nature of planing boats, and their proportionality between angle of attack and induced drag, one can see how shallowness causes sudden increases in resistance and sinkage. The trend of the shape of all curves is to slowly converge to that of the deep-water condition as $\nabla / A_{p} h^{h} \rightarrow 0$. 


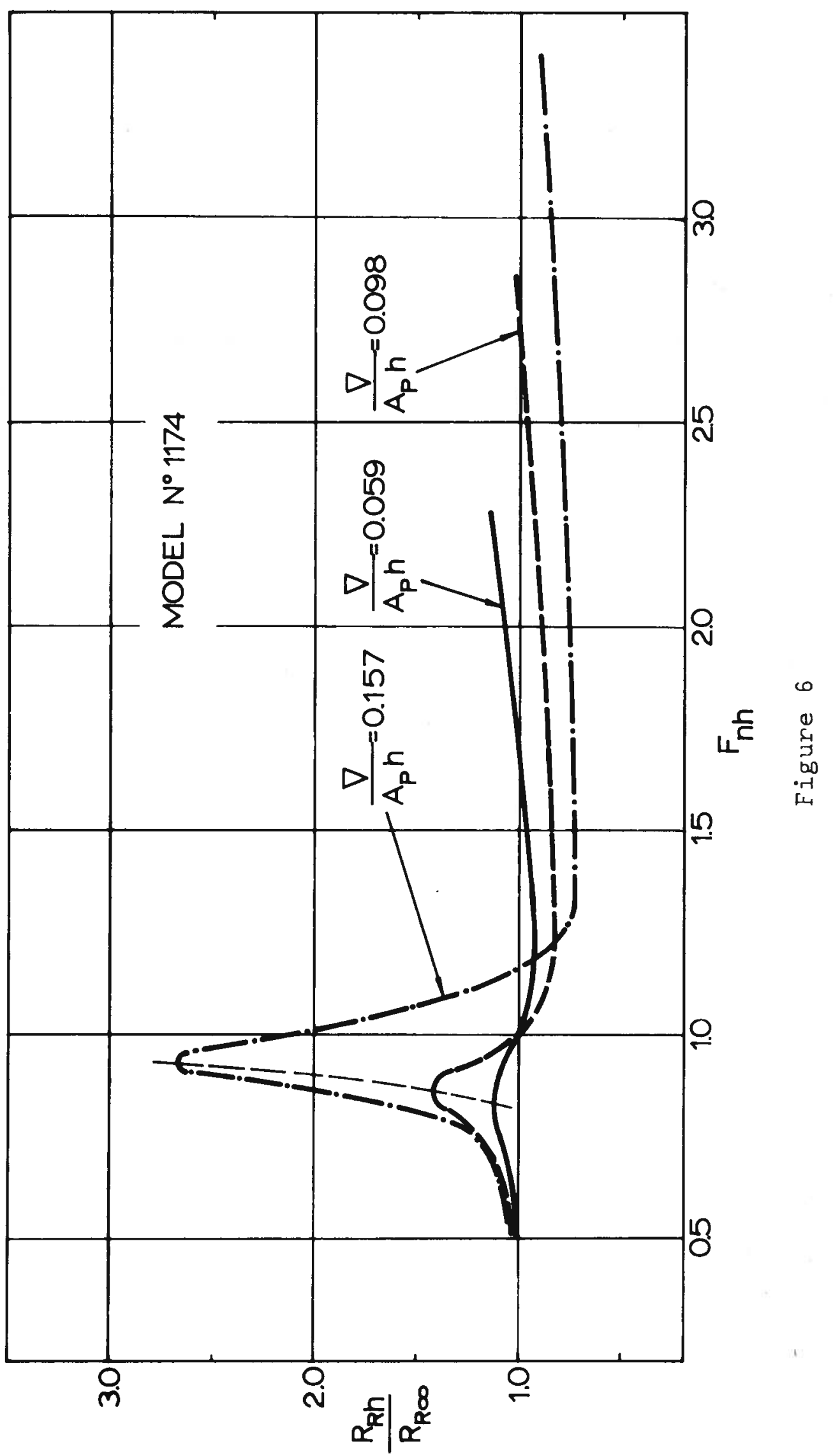


It is interesting to note that the curves in Figure 6 for each value of $\nabla / A_{P} h$ are drawn through the data for all LCG!s, there being little variation due to LCG, even though one might anticipate otherwise from the previous reasoning. However, for each curve both the $R_{R h}$ and $R_{R \infty}$ on the ordinate scale in Figure 6 are taken for the same LCG. Therefore, the change in angle of attack is not influenced by LCG position for a given shallowwater depth.

On Figure 6 , in the supercritical region the curves drop below $R_{R h} / R_{R_{\infty}}=1$, representing a power savings. Indeed, that phenomenon is also governed primarily by $F_{n h}$ and secondarily by $\nabla / A_{P} h$. In this supercritical domain, the local flow contributes to greater dynamic lift, which is also shown by the sinkage curves. Eventually all curves in Figure 6 go above $R_{R h} / R_{R_{\infty}}=1$ at high $F_{n h}$, at which time the adverse wave formations again become dominant.

Presentation of power curves was necessary for practical application. In Figures 7 and $8, \mathrm{P}_{\mathrm{E}}$ (effective horsepower) is plotted against $V_{K}$ (speed in knots), holding the water depth constant and showing the power variation with LCG locations. In shallow water the optimum LCG position does not seem to vary significantly from 


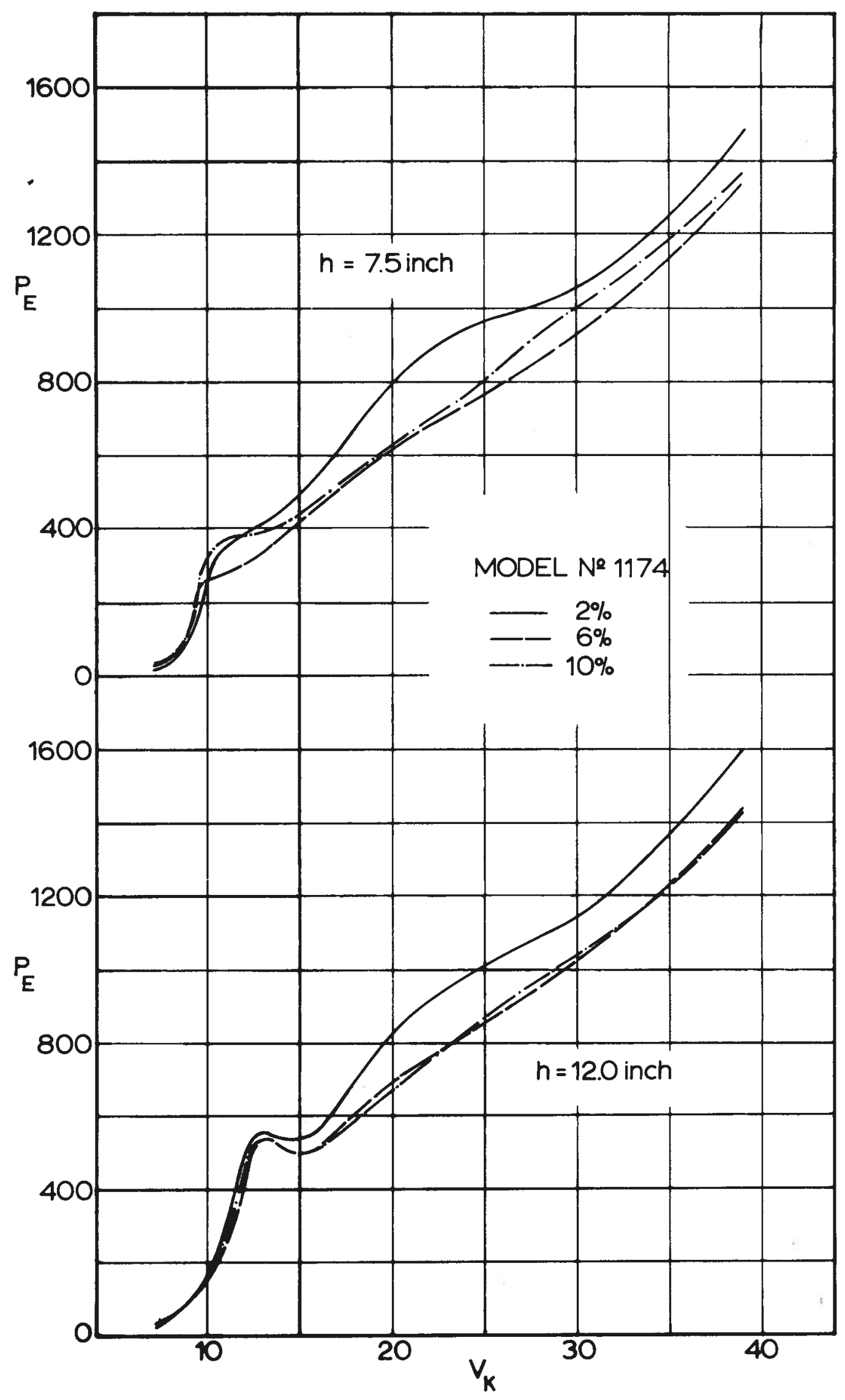

Figure 7 


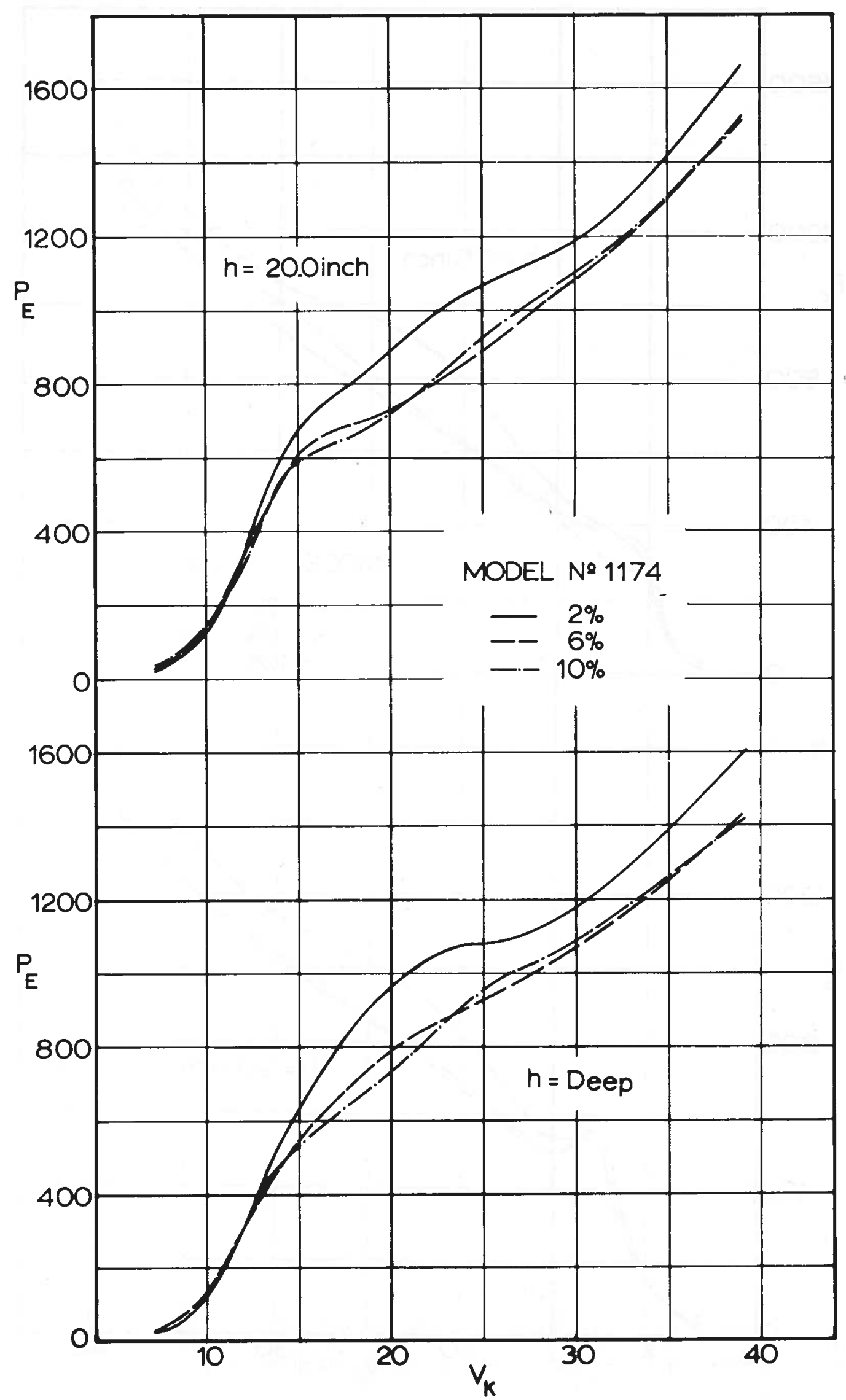

Figure 8 
what the deep-water results show. At critical speeds, power may be increased by a factor of two or more, while at supercritical speeds power reductions of $10 \%-15 \%$ may be anticipated. 


\section{REFERENCES}

1. "Resistance Tests of a Systematic Series of Planing Hull Forms," by Eugene P. Clement and Donald L. Blount, Trans. SNAME, Vol. 71, 1963.

2. Principles of Naval Architecture, Edited by J. P. Comstock, Published by SNAME, 1967.

3. "Systematishe Untersuchungen von Kleinschiffsformen auf flachem Wasser im unter- und uberuritishen Geschwindigkeitsbereich," No. 617, by Prof. Dipl.-Ing. Wilhelm Sturtzel und Dr.-Ing. Werner Graff, Forschungsberichte des Wirtschafts- und Verkehrsministeriums Nordrhein-Westfalen.

4. Class notes from NA 401: "SmaJ.1 Craft Design," Taught by J. L. Moss, and NA 42 0: "Resistance, Propulsion, and Propellers," Taught by Dr. S. D. Sharma, The University of Michigan, College of Engineering, Department of Naval Architecture and Marine Engineering, Winter Term 1969. 
APPENDIX 


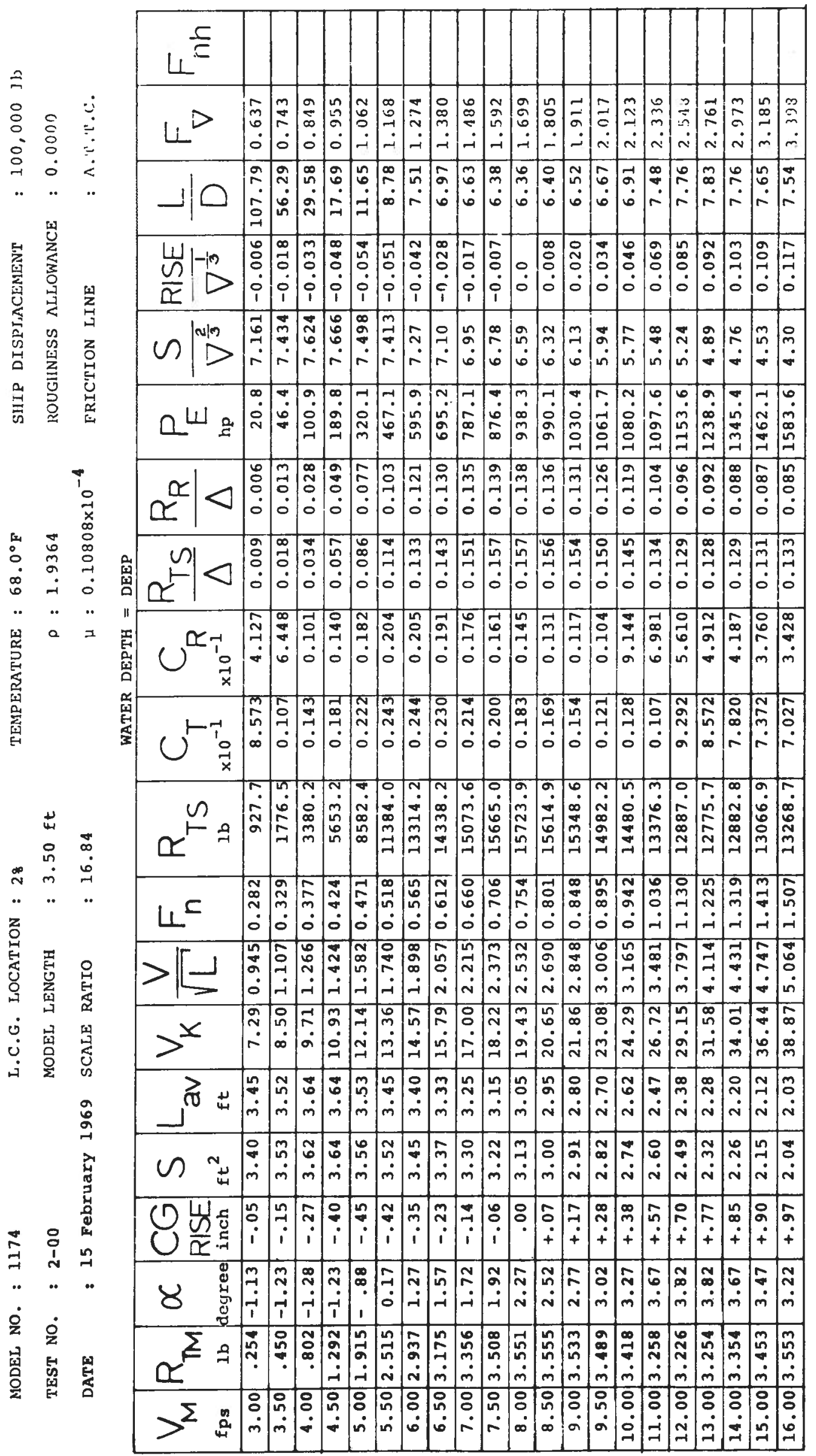




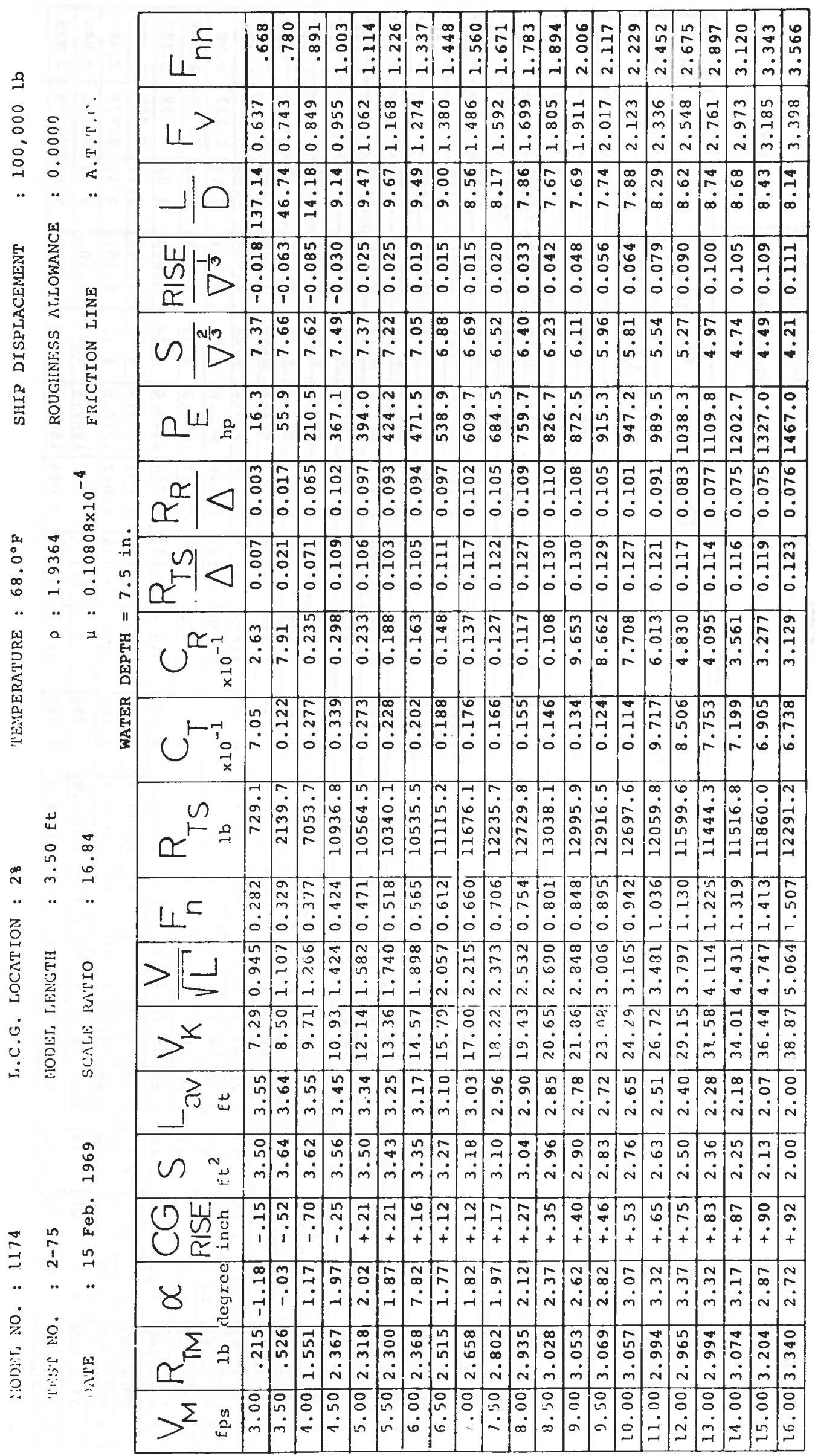




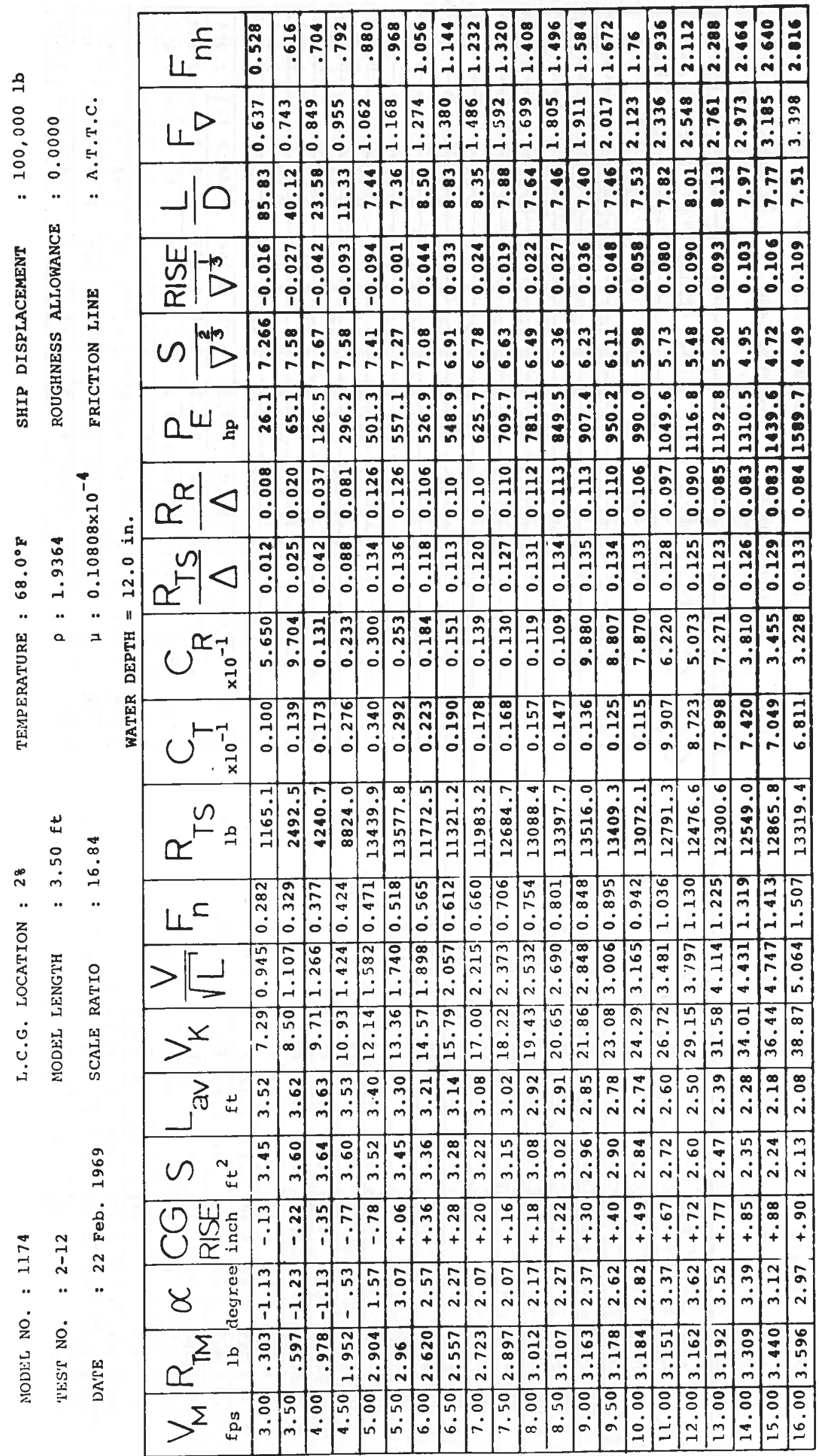




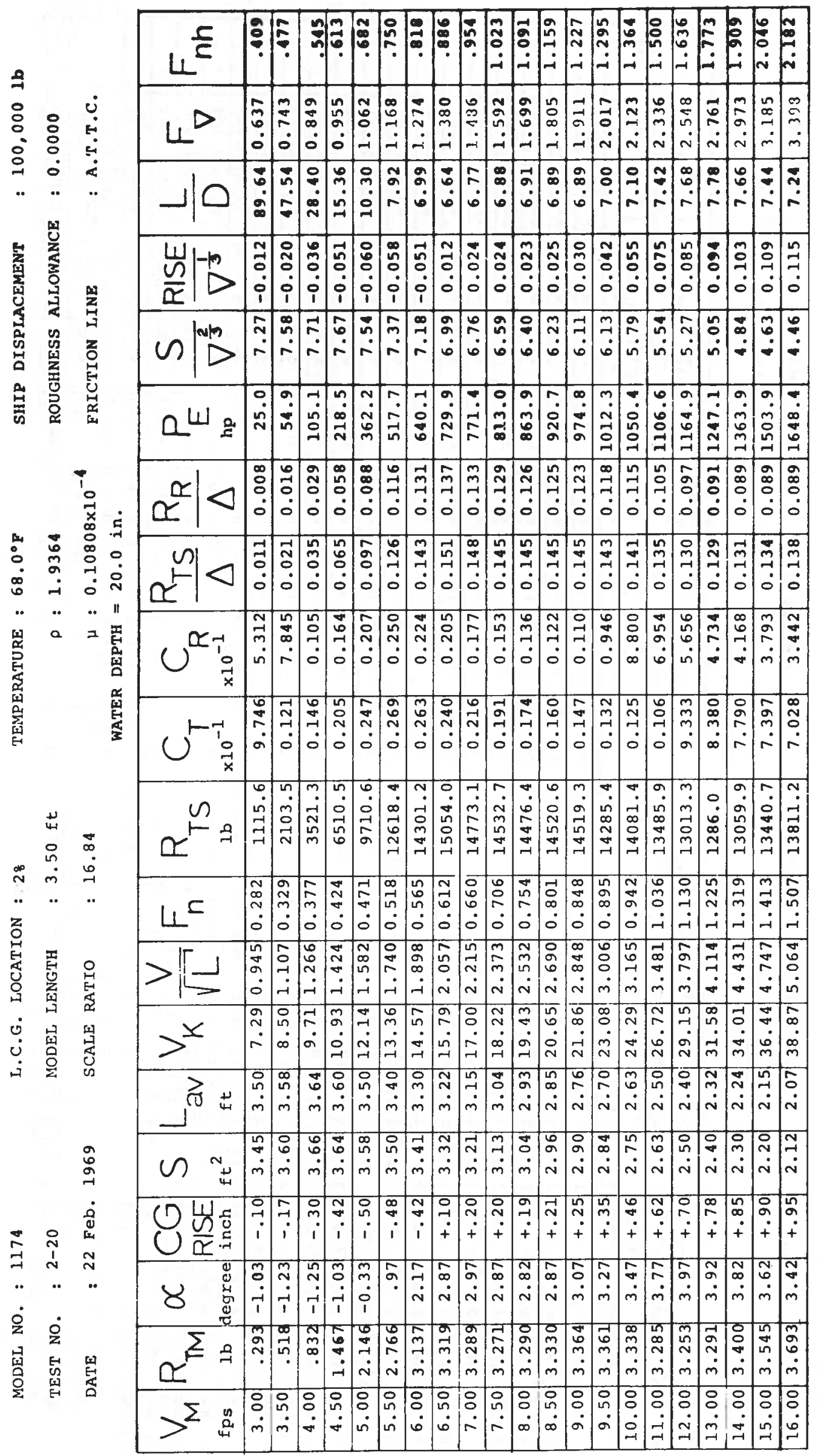




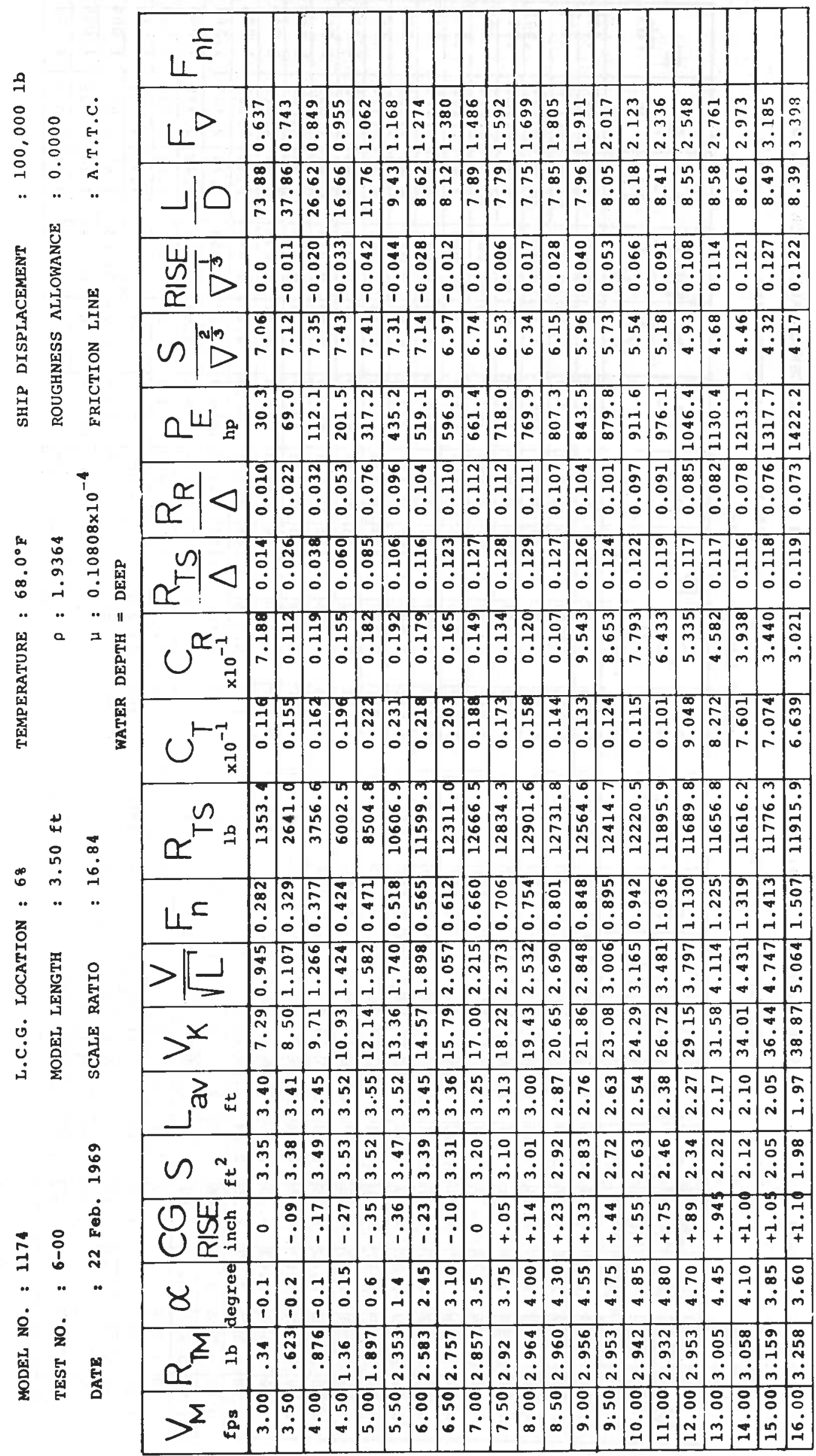




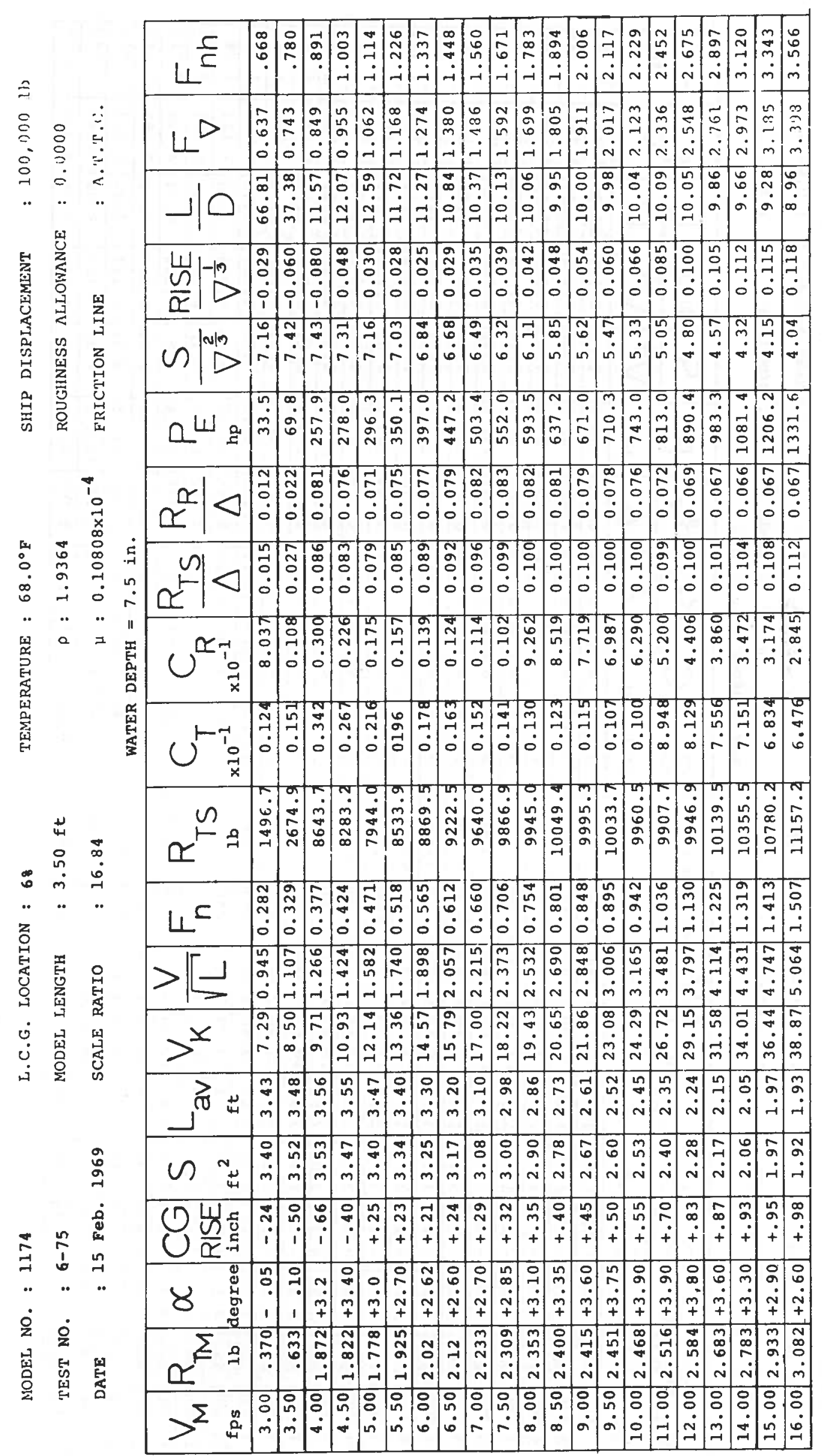




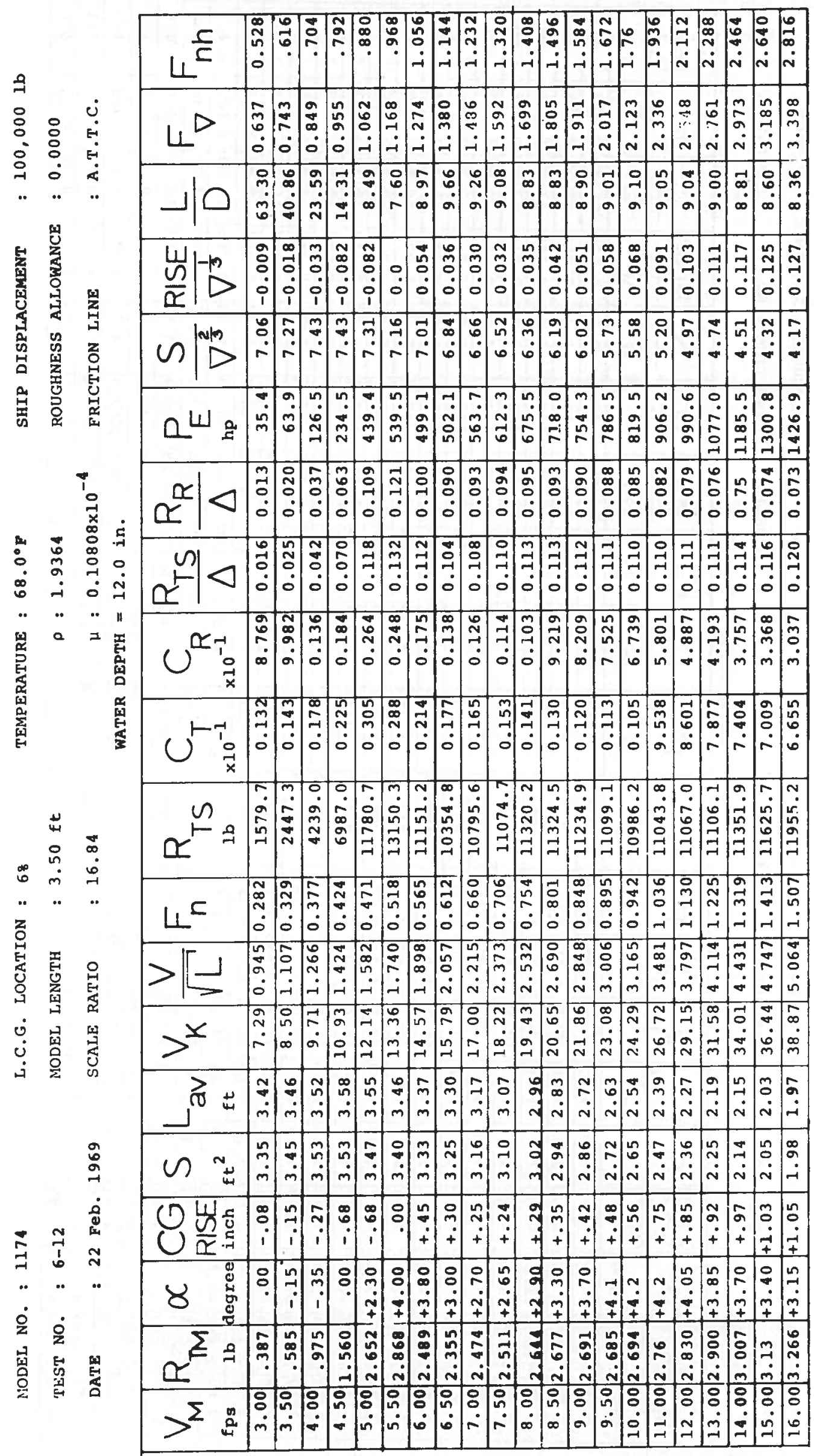




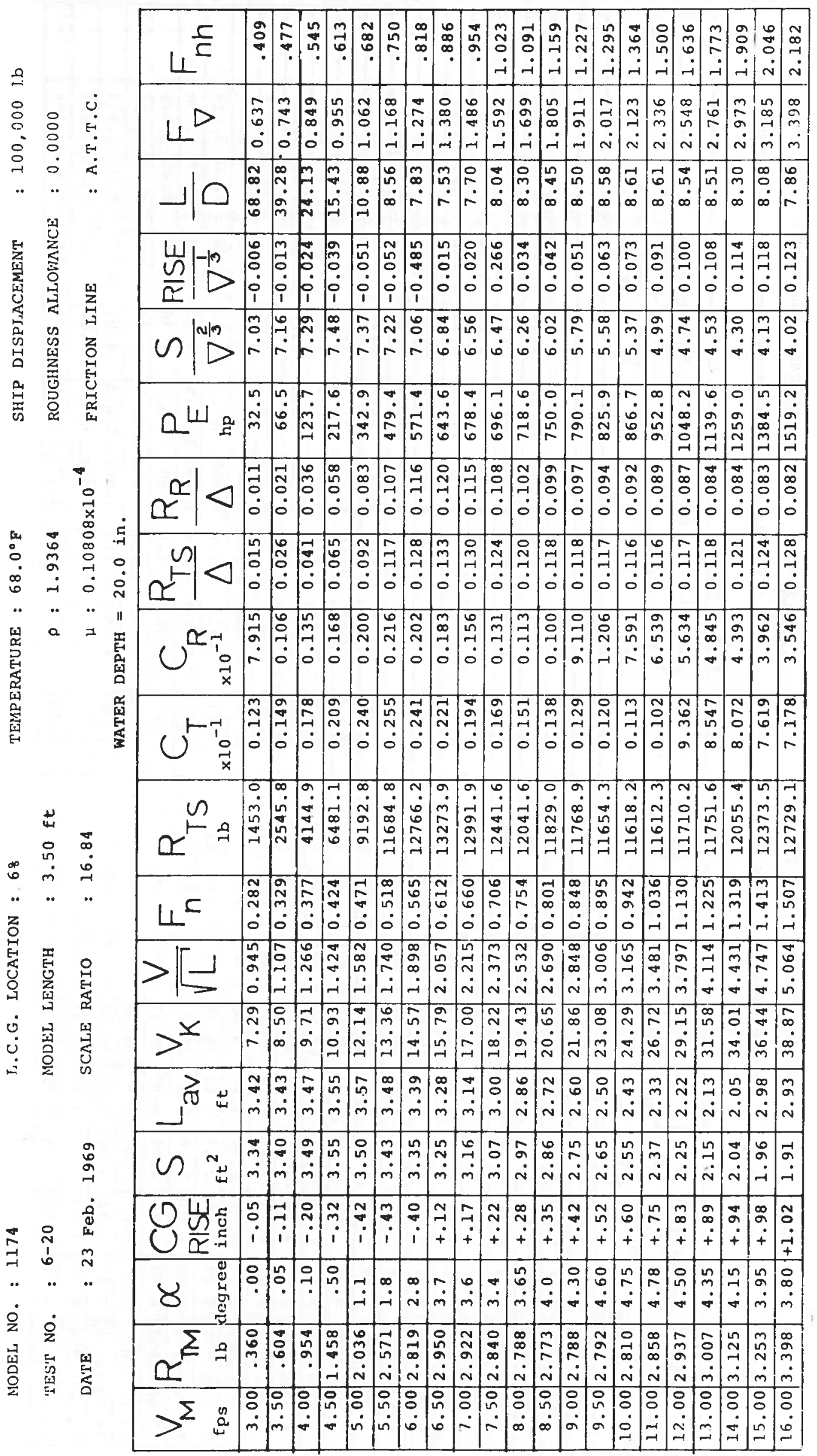




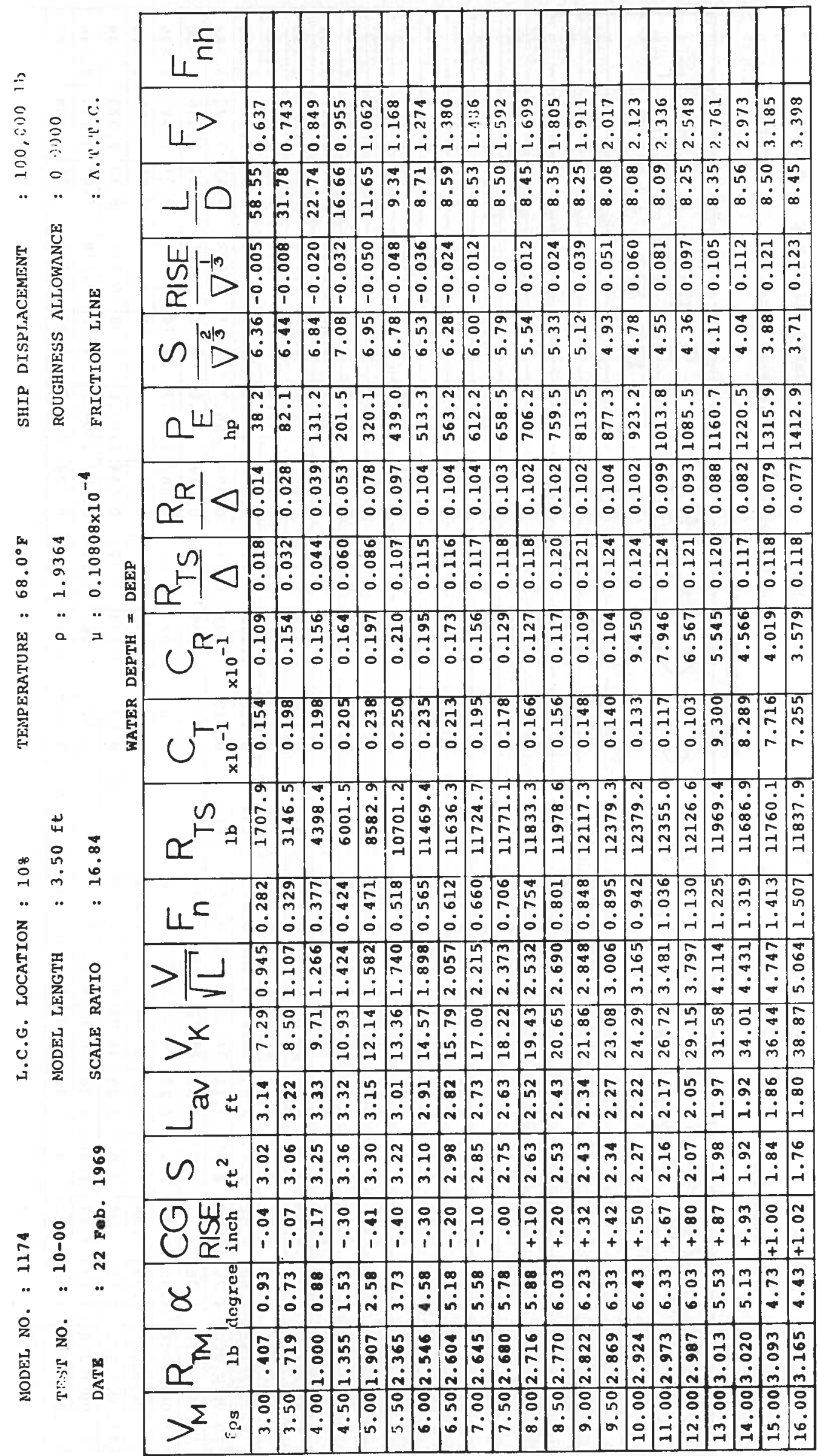




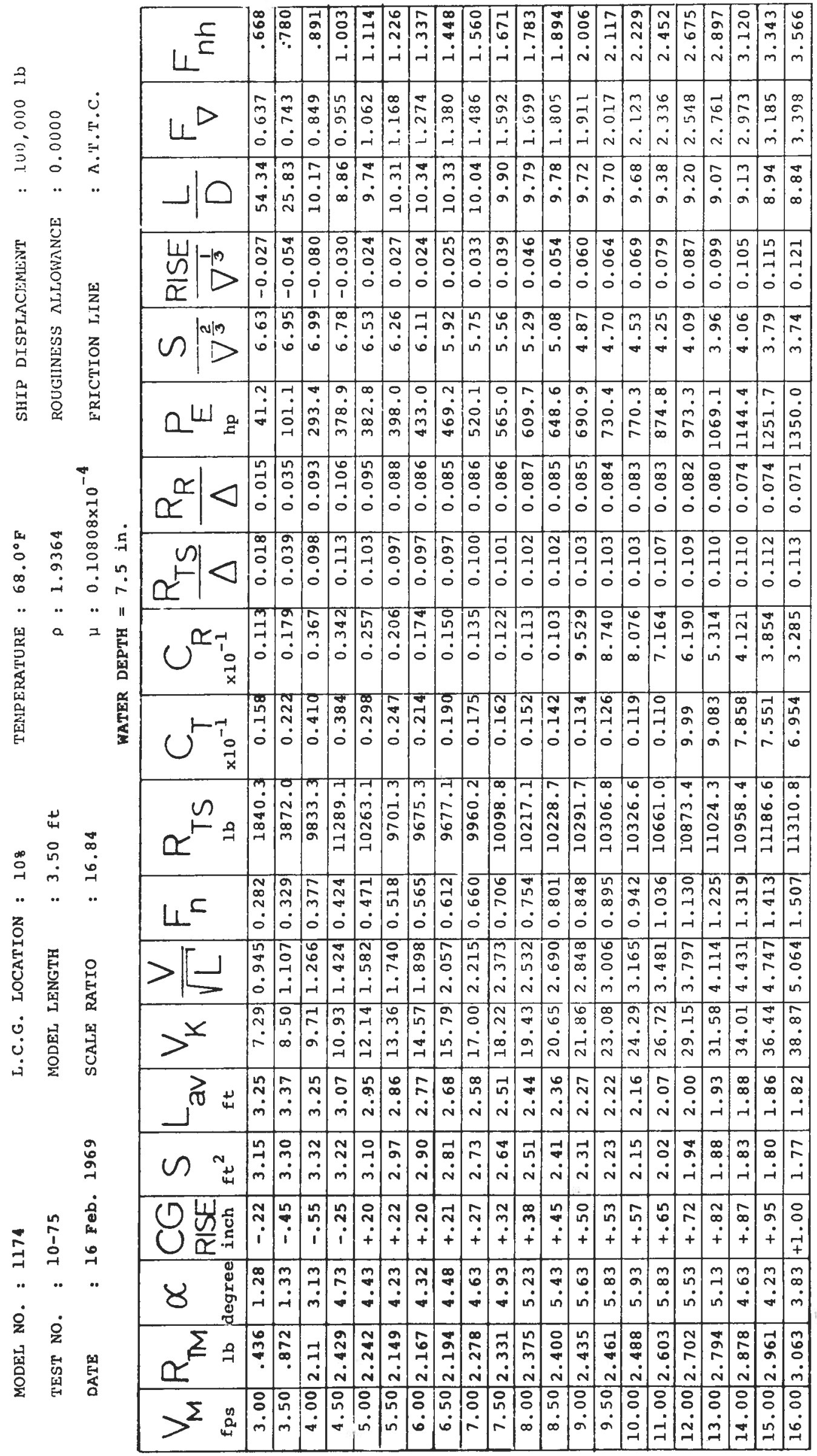




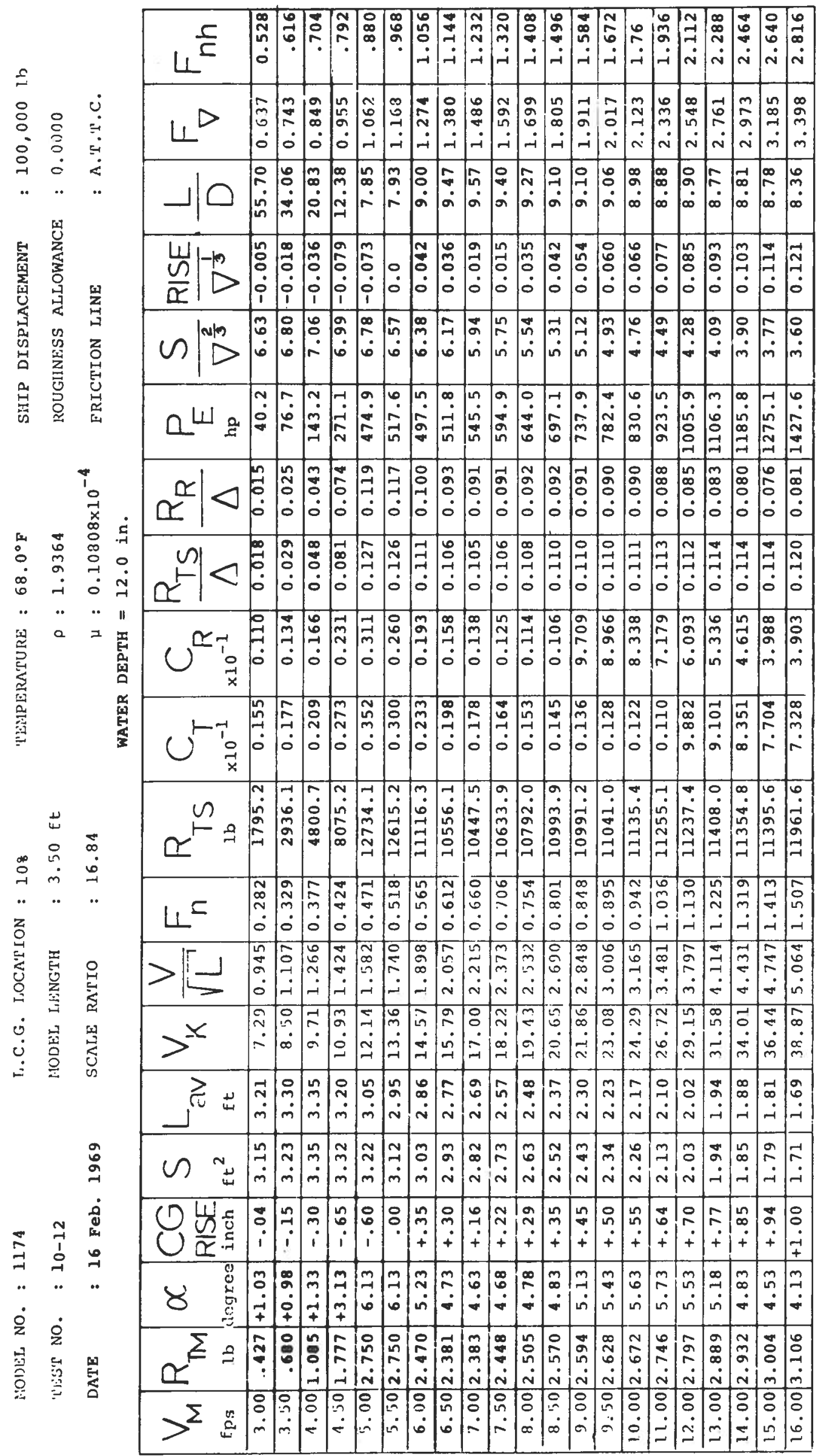




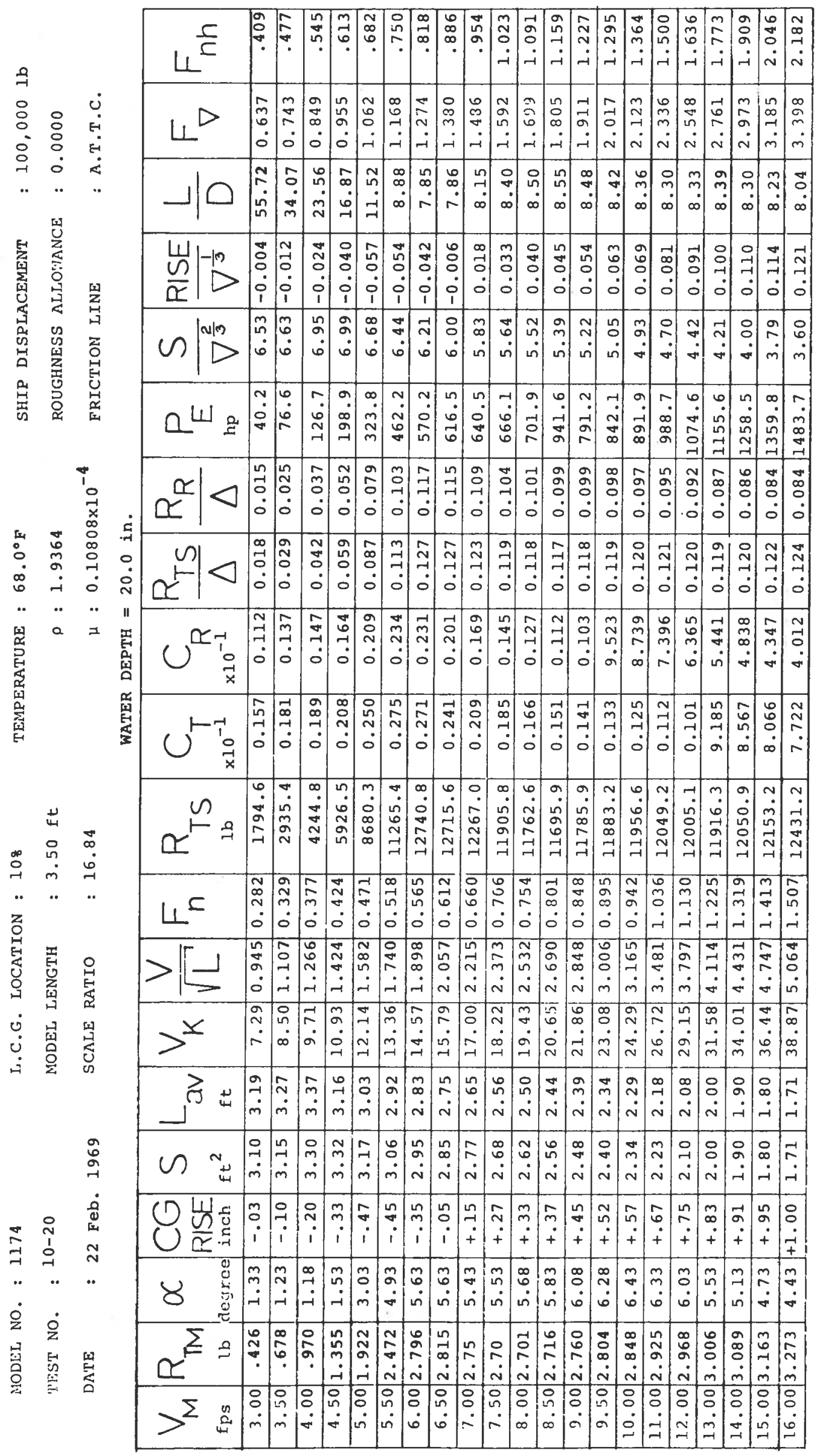


$h=20$
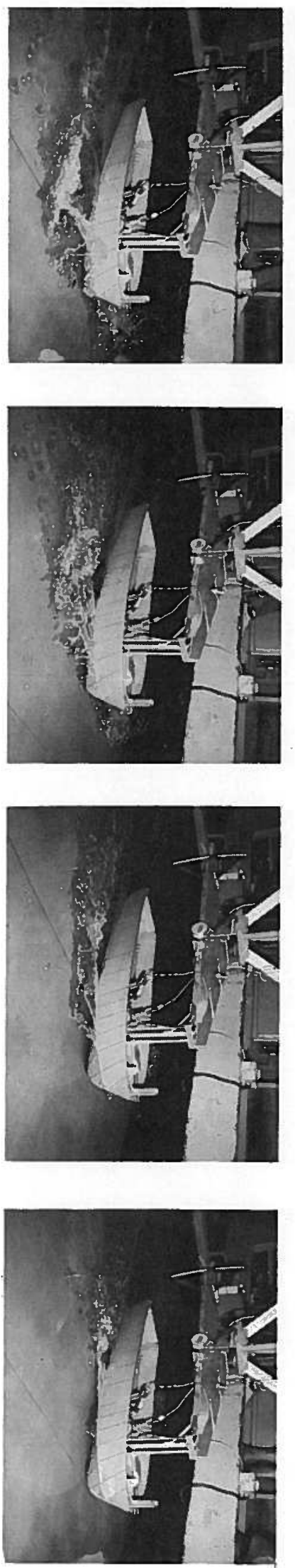

$h=12$
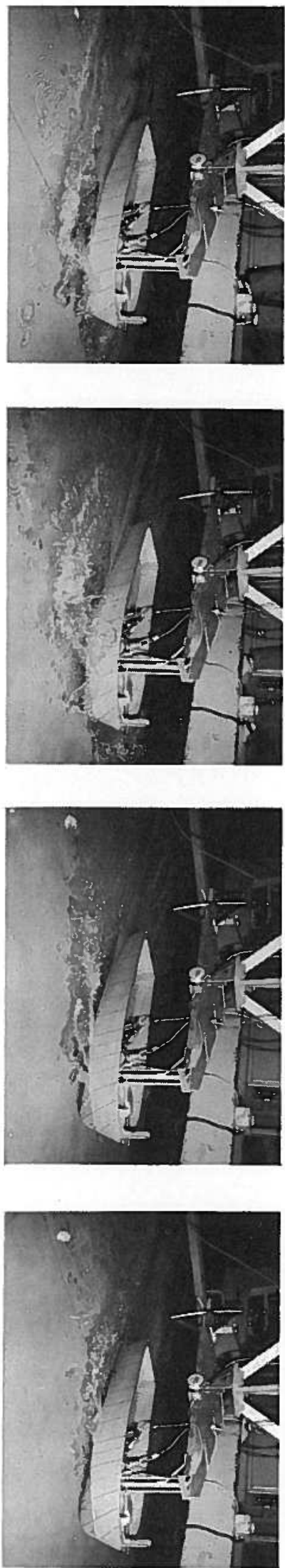

$h=7.5$
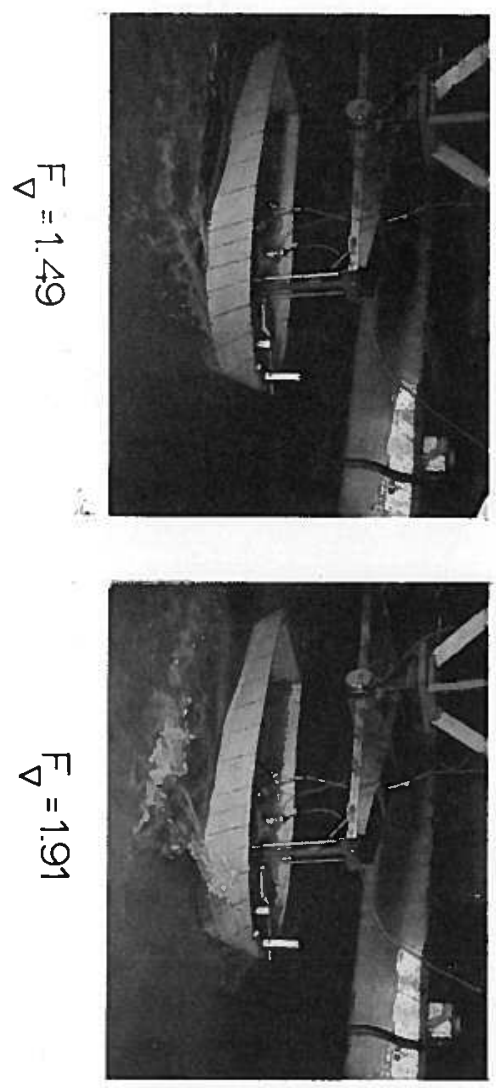

$\tilde{\Omega}$
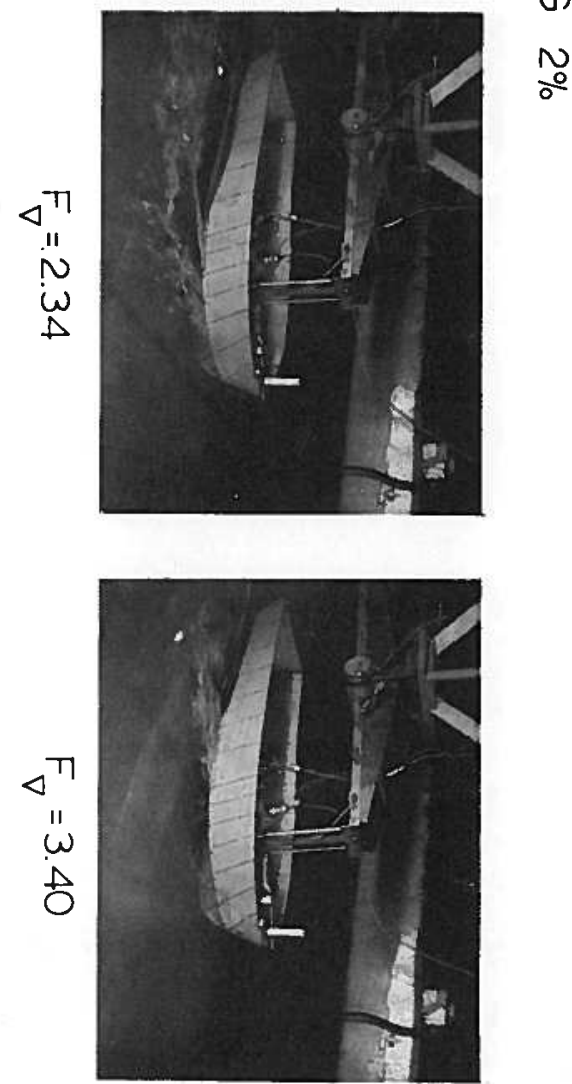
$h=20$
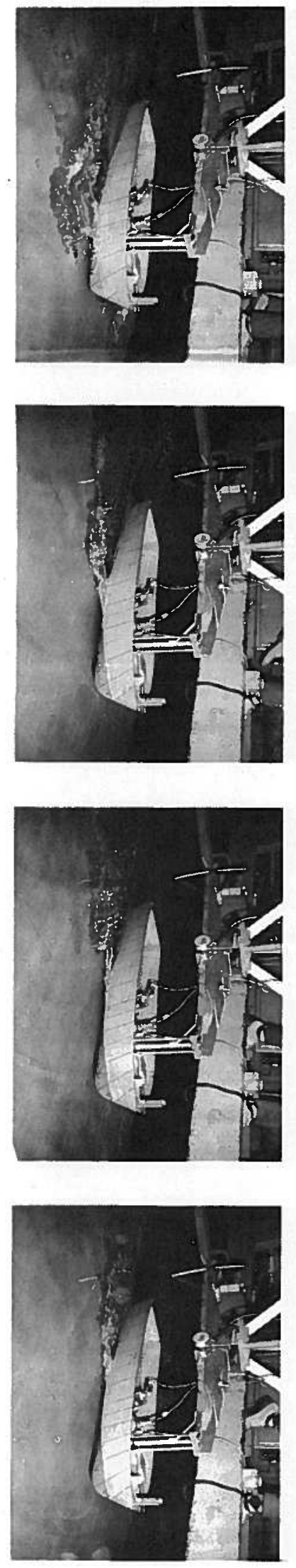

$n=12$
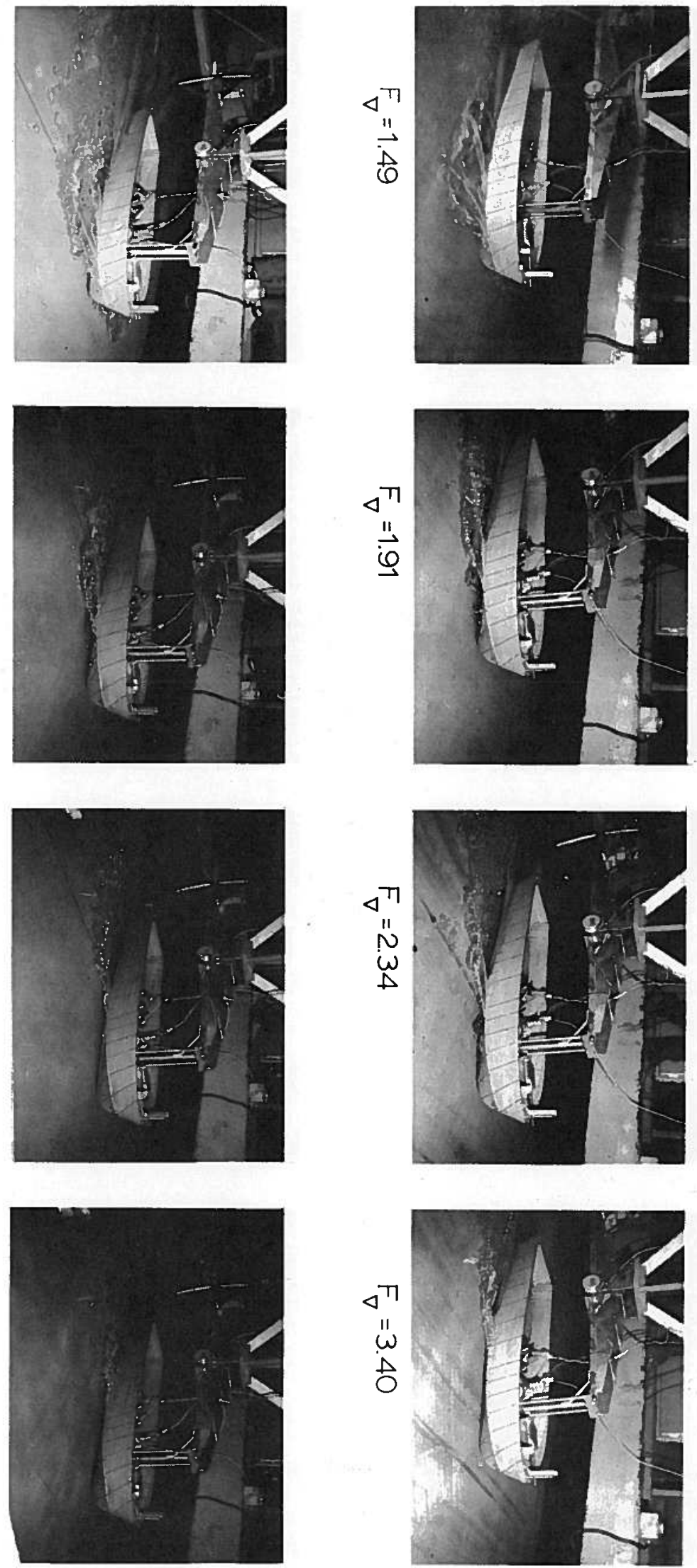

กิ

$h=7.5$

응

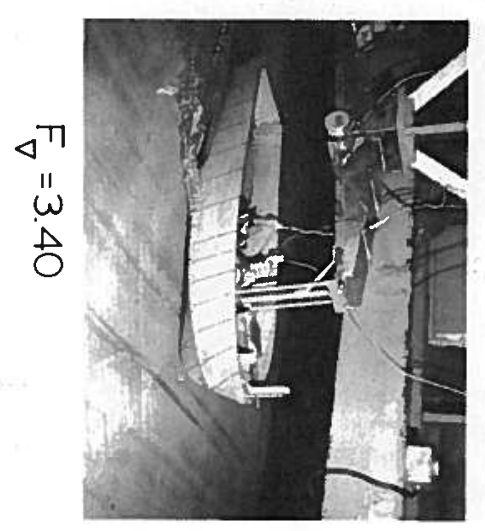


$h=20$
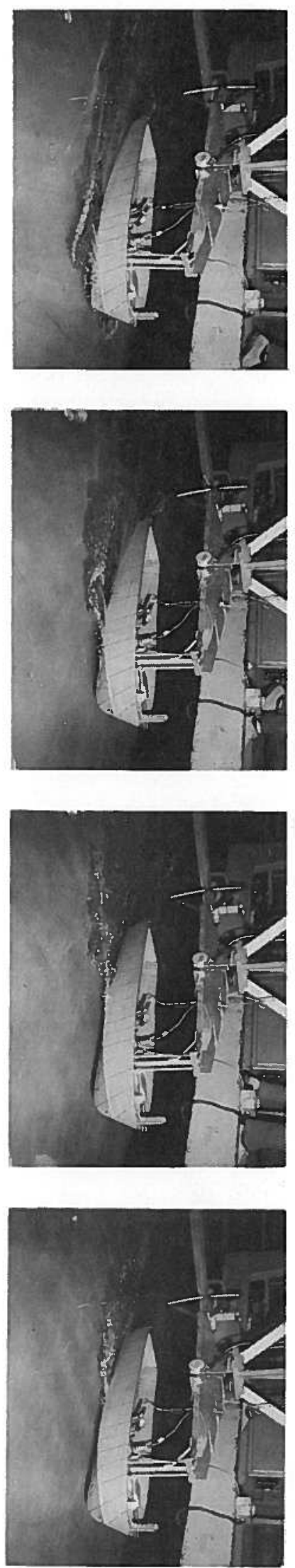

$h=12$
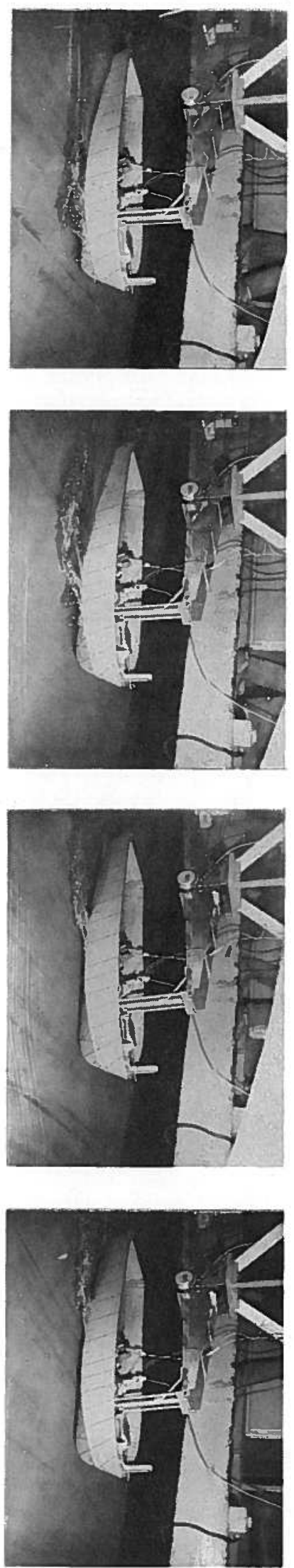

$h=7.5$
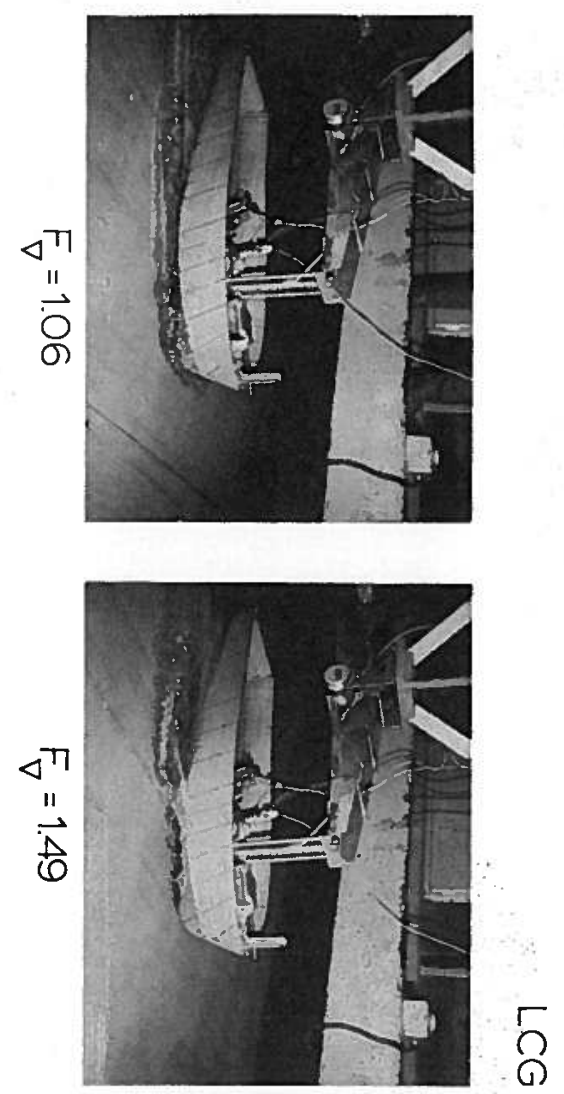

कृ

$\Delta \pi$
$n$
$\tilde{\omega}$
$\Delta$
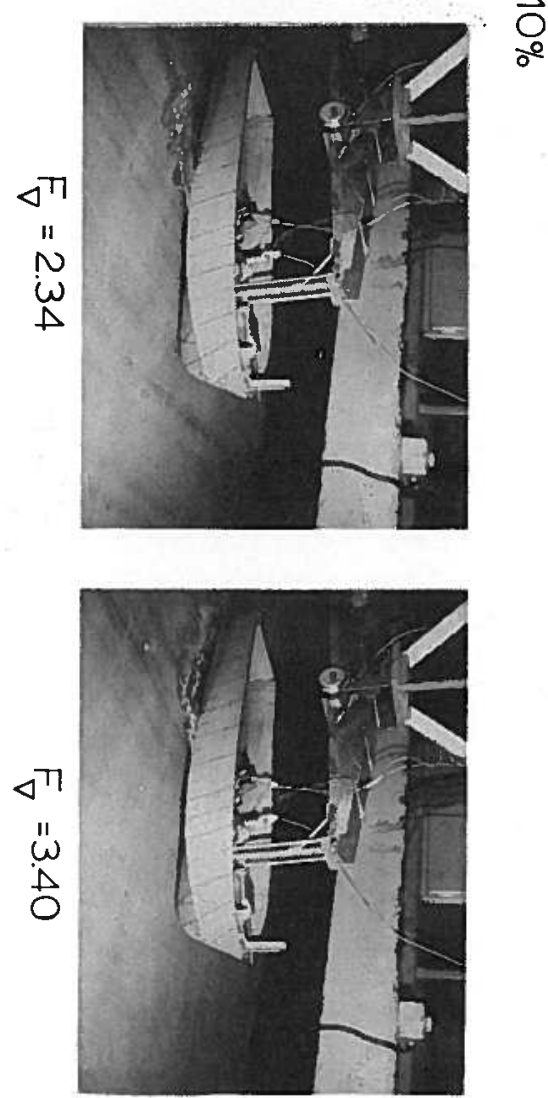

The University of Michigan is an equal opportunity/
affirmative action employer. Under applicable federal and
state laws, including Title IX of the Education Amendments
of 1972 , the University does not discriminate on the basis of sex, race or other prohibited matters in employment, in th , in educational programs and activities, or in admissions. Inquiries or complaints may be addressed to the University's Director of Affirmative Action and Title IX Compliance: Dr. Gwendolyn C. Baker, 5072 Administration Building 763-0235. 